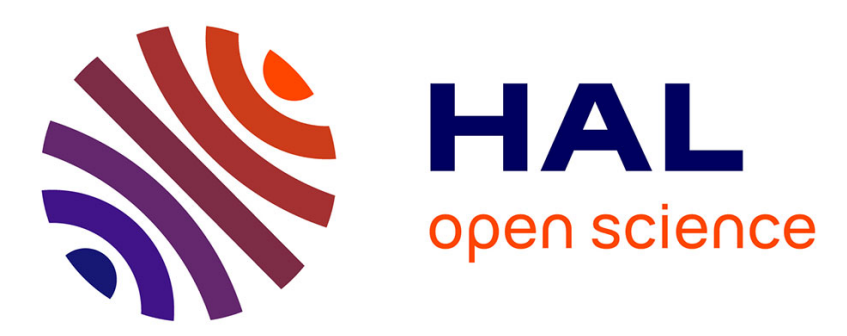

\title{
The proper generalized decomposition for the simulation of delamination using cohesive zone model
}

Sondes Metoui, Etienne Pruliere, Amine Ammar, Frédéric Dau, Ivan Iordanoff

\section{To cite this version:}

Sondes Metoui, Etienne Pruliere, Amine Ammar, Frédéric Dau, Ivan Iordanoff. The proper generalized decomposition for the simulation of delamination using cohesive zone model. International Journal for Numerical Methods in Engineering, 2014, 99 (13), pp.1000-1022. 10.1002/nme.4732 . hal-01062894

\section{HAL Id: hal-01062894 https://hal.science/hal-01062894}

Submitted on 10 Sep 2014

HAL is a multi-disciplinary open access archive for the deposit and dissemination of scientific research documents, whether they are published or not. The documents may come from teaching and research institutions in France or abroad, or from public or private research centers.
L'archive ouverte pluridisciplinaire HAL, est destinée au dépôt et à la diffusion de documents scientifiques de niveau recherche, publiés ou non, émanant des établissements d'enseignement et de recherche français ou étrangers, des laboratoires publics ou privés. 


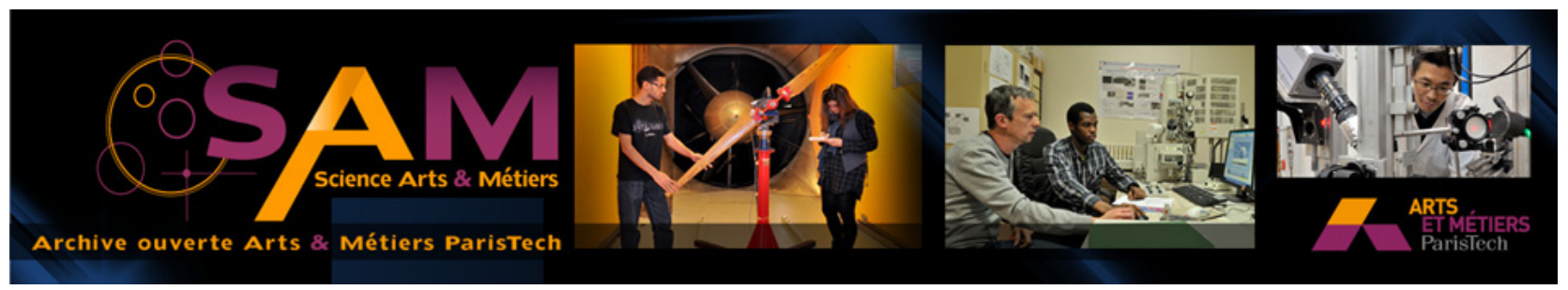

Science Arts \& Métiers (SAM)

is an open access repository that collects the work of Arts et Métiers ParisTech researchers and makes it freely available over the web where possible.

This is an author-deposited version published in: http://sam.ensam.eu

Handle ID: .http://hdl.handle.net/10985/8491

\section{To cite this version :}

Sondes METOUI, Etienne PRULIERE, Amine AMMAR, Frédéric DAU, Ivan IORDANOFF - The proper generalized decomposition for the simulation of delamination using cohesive zone model INTERNATIONAL JOURNAL FOR NUMERICAL METHODS IN ENGINEERING - Vol. 99, n¹3, p.1000-1022 - 2014 


\title{
The proper generalized decomposition for the simulation of delamination using cohesive zone model
}

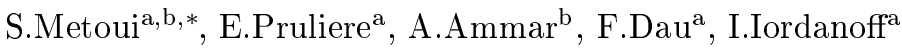 \\ ${ }^{a}$ Arts et Métiers ParisTech, Centre de Bordeaux, I2M-DuMAS, Esplanade des Arts et \\ Métiers, Talence 33405, France \\ ${ }^{b}$ Arts et Métiers Paris Tech, Centre d'Angers, LAMPA, 2 Boulevard de Ronceray, 49035 \\ Angers Cedex 01 , France
}

\begin{abstract}
The use of cohesive zone models is an efficient way to treat the damage, especially when the crack path is known a priori. This is the case in the modeling of delamination in composite laminates. However, the simulations using cohesive zone models are expensive in a computational point of view. When using implicit time integration scheme or when solving static problems, the non-linearity related to the cohesive model requires many iterations before reaching convergence. In explicit approaches, the time step stability condition also requires an important number of iterations.

In this article, a new approach based on a separated representation of the solution is proposed. The Proper Generalized Decomposition is used to build the solution. This technique, coupled with a cohesive zone model, allows a significant reduction of the computational cost. The results approximated with the PGD are very close to the ones obtained using the classical finite element approach.
\end{abstract}

Keywords: Proper Generalized Decomposition, Cohesive Zone Model, Composite laminates, Delamination, Interface fracture

\section{Introduction and motivation}

Composite laminates are subject to intralaminar failure mechanisms, such as fiber fracture or matrix cracking, and interlaminar failure, such as delamination. Failure can occur due to static, cyclic or impact loadings and can be related to manufacturing defects. When a composite structure is impacted (tool drops, hail, ...) small and hardly detectable damages can appear and evolve in time

\footnotetext{
*Corresponding author

** Principal corresponding author

Email addresses: sondes.metoui@ensam.eu (S.Metoui), Etienne.Pruliere@ensam.eu (E.Pruliere), amine.ammar@ensam.eu (A.Ammar), frederic.dau@ensam.eu (F.Dau), ivan. iordanoff@ensam.eu (I.Iordanoff)
}

Preprint submitted to International Journal for Numerical Methods in EngineeringMay 28, 2014 
before being critical. The modeling of damage appearance and evolution is very important to assess the durability of structures. Delamination is one of the most critical and frequent damage in laminated composites and must be modeled with careful attention.

Different approaches were developed to study delamination, or in general the crack appearance and propagation in a material where the crack path is previously known.

The fracture mechanic approaches have been initially developed by Griffith and Irwin to explain the failure of brittle materials when the non linearities are negligible. In practice, most materials possess a non linear zone in the crack tip. It is characterized by a softening behavior, and is referred to as the fracture process zone. With a small process zone size, the Linear Elastic Fracture Mechanics approaches (LEFM) have been proven to be reliable in predicting the propagation of a pre-existing crack using the Finite Element Method (FEM).

This is then necessary to calculate the energy needed to let the crack propagate after the onset of delamination, which is called the energy release rate. The most suited fracture mechanics approach to evaluate this energy is the Virtual Crack Closure Technique (VCCT), which uses the nodal forces and displacements computed by FEM [1, 2]. The VCCT method is based on Irwin's crack closure integral [3], and assumes that the crack length increment remains small. This technique becomes more effective when the mesh is refined and requires the previous knowledge of the crack location as well as its direction of propagation [4]. However, the VCCT presents many difficulties when implemented within a finite element code. For instance, it requires remeshing at the crack tip during the growth of delamination.

To overcome the limitations of the LEFM, other approaches have been proposed. One of these approaches is the Cohesive Zone Models (CZM). It is based on the use of interfacial finite elements between the layers of the laminated composite. The CZM assumes the presence of a process zone ahead of the crack tip. The cohesive elements are delimited by two cohesive surfaces linked together by cohesive forces. The concept of this approach comes from the Dugdale and Barenblatt cohesive models $[5,6]$ and was also used by Needleman. Compared to the VCCT method, and in conjunction with the FEM $[7,8]$, the CZM has the ability to predict both the onset and the propagation of the crack. It combines the application of a strength criterion to predict the onset of decohesion, together with an energy criterion to model the propagation. The relation between the relative separation of the cohesive surfaces and the cohesive stresses is described by a constitutive law. This constitutive equation is based on the assumption that when the separation between the interfaces increases, the cohesive stresses reaches the onset, then progressively decreases to zero and complete fracture.

The use of the CZM in association with the FEM offers the opportunity to study the crack propagation in different modes. These fracture modes can be classified as a normal-opening mode (mode I), and two shear sliding modes (mode II and mode III). The crack can occur in any of these modes, or as a combination of them. The use of cohesive elements in FEM codes is certainly 
the most rigorous strategy to simulate damages like delamination.

However, the implementation of the CZM in finite element codes has several disadvantages. First, it can lead to convergence problems, numerical instabilities, mesh sensitivity and computing inefficiency in the presence of significant materiel non-linearities. Secondly, a large number of finite element calculations is often required to evaluate the sensitivity of the model to the interface parameters. Moreover, a relatively refined mesh is needed to increase accuracy [9], but this could lead to excessive computation time when applied to industrial structures. Furthermore, industrial structures are generally composed of a large number of layers, which requires a high number of interface elements, leading to increased the computational cost as well. In practice, CZM are almost always restricted to academic applications. There is a real need in efficient numerical solvers, that can significantly reduce the cost of this type of models.

In this paper, a new approach based on Reduced Order Modeling (ROM) is proposed to treat the delamination in composite laminates. One famous and efficient model reduction method is the Proper Generalized Decomposition (PGD) $[10,11]$. The use of the PGD discretization leads to major reductions in computing time and storage cost, especially when the resulting mesh involves a high number of degrees of freedom. This paper proposes a way to implement the CZM in the context of the PGD and suggests some usual numerical tests to evaluate the performance of the method in terms of computational cost and results precision.

The PGD is based on a separated representations of the solution. It enables the reduction in size of the multidimensional and parametric problems $[12,13]$. The PGD philosophy was originally proposed by Ladeveze with spacetime problems in the context of the LATIN (LArge Time Increment) method, which was called radial decomposition $[14,15]$. The separated representation of the solution $(u)$ is built as a finite sum of $N$ functional products $\left(F^{i}\right)$ involving $D$ functions of each coordinate $\left(x_{1}, \ldots, x_{D}\right)$. This can be written as:

$$
u\left(x_{1}, \ldots, x_{D}\right) \approx \sum_{i=1}^{N} F_{1}^{i}\left(x_{1}\right) \times \ldots \times F_{D}^{i}\left(x_{D}\right)
$$

These functions are a priori unknown. This representation is then injected in the weak form of the problem and the non-linear equations are solved. This strategy was successfully employed by Ammar et al. $[16,17]$ for the kinetic theory description of complex fluids. Separated representations have also been used for solving the chemical master equation [18] and stochastic equations within the Brownian Configuration Field framework [19]. The PGD has also been applied in other studies for thermal problems in composite materials [20] and to efficiently compute full 3D solutions using in-plane/out-of-plane separated representation of composite laminates [21]. The PGD has demonstrated its capability to study stochastic parametric partial differential equations [22, 23]. It has been used then by Vidal $[24,25]$ for laminated and sandwich composite plates modeling. Where, the comparison between the PGD and the FEM showed good agreement. 
The use of CZM in the context of the PGD brings some difficulties that are treated in this paper. Firstly, the classical cohesive elements are not directly compatible with the separated representation and therefore the numerical description of the cohesive zone must be rethought. Another difficulty raises when trying to represent local singularities for which the PGD is generally unadapted. There is no evidence that the method will be able to represent finely the comportment in the crack tip.

Therefore, some test cases in different fracture modes have to be implemented and compared with reference values to ensure the precision of the method. DCB (Double Cantilever Beam), ELS (End Loaded Split) and MMF (Mixed Mode Flexure) fracture tests were used in order to assess the quality of numerical predictions under pure mode I, pure mode II and mixed mode, respectively. The PGD-CZM model is compared to a classical FEM with CZM (FEM-CZM) as well as to analytical solutions. From a computational point of view, both models were implemented in the same way, with the same programming language, and with the same set of parameters. Both models were studied with a bilinear constitutive cohesive law to define the interfacial behaviour.

\section{Problem Formulation}

\subsection{Constitutive cohesive law under single mode delamination}

The formulation of the cohesive zone model used in this work is the Crisfield law $[26,27]$ shown in Figure 1. It is used to describe the behaviour of the interface, which presents linear elastic and linear softening behaviour. The process of degradation begins when the stresses satisfy one imposed damage initiation criterion. The Crisfield law supposes that, under strain reversal, the material unloads toward the origin. A two-parameter bilinear cohesive law was defined, for each pure mode. These two parameters are the maximum stress $\left(\sigma_{c}\right.$ and $\left.\tau_{c}\right)$ and the energy release rate $\left(G_{I c}\right.$ and $\left.G_{I I c}\right)$ for respectively mode I and mode II.

The critical value of the energy release rate is equal to the area under the interfacial stress-separation curve. $K_{I}$ and $K_{I I}$ are the interfaces element stiffness. The critical separations $\left(\delta_{c}^{I}\right.$ and $\left.\delta_{c}^{I I}\right)$ are defined when the interfacial stress reaches maximum, and the maximum separations $\left(\delta_{m}^{I}\right.$ and $\left.\delta_{m}^{I I}\right)$ are defined when the stress becomes zero. These separations can be evaluated by the following expressions:

$$
\begin{gathered}
\delta_{c}^{I}=\frac{\sigma_{c}}{K_{I}}, \quad \delta_{c}^{I I}=\frac{\tau_{c}}{K_{I I}} \\
\delta_{m}^{I}=\frac{2 G_{I c}}{\sigma_{c}}, \quad \delta_{m}^{I I}=\frac{2 G_{I I c}}{\tau_{c}}
\end{gathered}
$$

The relation between local separation and interface stress, shown in Figure 1, can be expressed as: 


$$
\begin{gathered}
\sigma_{z z}, \tau_{x z}=\left\{\begin{array}{cc}
K_{i} \delta_{i} & \delta_{i}<\delta_{c}^{i} \\
\left(1-d_{i}\right) K_{i} \delta_{i} & \delta_{c}^{i} \leq \delta_{i}<\delta_{m}^{i} \\
0 & \delta_{i} \geq \delta_{m}^{i}
\end{array}\right. \\
d_{i}=\frac{\delta_{m}^{i}\left(\delta_{i}-\delta_{c}^{i}\right)}{\delta_{i}\left(\delta_{m}^{i}-\delta_{c}^{i}\right)}, \quad i=I, I I ; d_{i} \in[0,1]
\end{gathered}
$$

Where $\sigma_{z z}$ and $\tau_{x z}$ are the interlaminar normal and shear stress related to mode I (opening) and mode II (shear). $d_{i}$ is the damage variable, which represents the overall damage at the interface. Initially $d_{i}$ equals 0 and evolves from 0 to 1 after the initiation of the damage.

\subsection{Constitutive cohesive law under mixed mode delamination}

The description of delamination under mixed-mode loading requires: $(i)$ the definition of the interfacial stress and the critical energy release rate for each pure mode and, (ii) the proposition of criteria or laws relating these parameters for mixed loading [28]. From these laws, the critical and maximum separations $\left(\delta_{c}^{m}\right.$ and $\delta_{m}^{m}$ ) under mixed mode loading can be determined. Each failure mechanism consists of two parts: a damage initiation criterion and a damage evolution law.

The damage initiation can be predicted using the quadratic failure criterion, defined as:

$$
\left(\frac{\left\langle\sigma_{z z}\right\rangle_{+}}{\sigma_{c}}\right)^{2}+\left(\frac{\tau_{x z}}{\tau_{c}}\right)^{2}=1
$$

Where $\langle.\rangle_{+}$denotes the positive value.

This mixed-mode criterion assumes the coupling between the failure modes and considers that compressive normal stress has no influence on the delamination onset.

The "power law criterion" appears to be the most advisable in order to predict delamination propagation in carbone/epoxy composite laminates under mixed-mode loading. It states that the damage under mixed loading is governed by a power law interaction between the energies of pure modes, that is:

$$
\left(\frac{G_{I}}{G_{I c}}\right)^{2}+\left(\frac{G_{I I}}{G_{I I c}}\right)^{2}=1
$$

Where $G_{I}$ and $G_{I I}$ are the energy release rates respectively in mode I and mode II, $G_{I c}$ and $G_{I I c}$ are the critical energy release rates.

The total mixed mode relative displacement $\delta_{m}$ can be defined as the norm of the two normal and tangential relative displacements:

$$
\delta_{m}=\sqrt{\delta_{I I}^{2}+\left\langle\delta_{I}\right\rangle_{+}^{2}}
$$




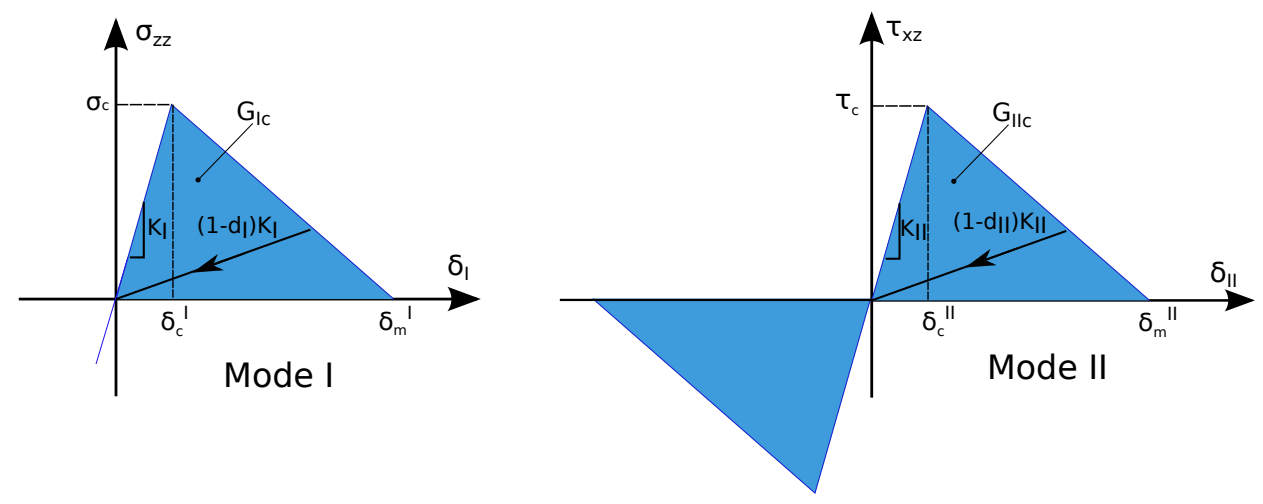

Figure 1: Cohesive law for the mode I and mode II.

\subsection{Kinematics of the interface element}

As mentioned in the introduction, two approaches ares compared in this work: the PGD-CZM and the FEM-CZM. These two approaches use different interface elements.

The cohesive surface of a laminate denoted $\Gamma_{c o h}$ is illustrated in Figure 2. In FEM, the cohesive surface is modeled using zero-thickness linear quadrilateral cohesive element with 4 -nodes. The zero-thickness linear 1D cohesive element shown in Figure 2 is used to simulate delamination problems in conjunction with the PGD model. The constitutive equations of these elements are mentioned in the previous subsections in the case of single or mixed mode delamination.

The displacement discontinuity $\delta$ across the interface $\Gamma_{c o h}$ can be expressed in terms of the displacement vector $\mathbf{u}$ computed on two sides of the discontinuity $\left(\mathbf{u}^{+}\right.$for the upper side and $\mathbf{u}^{-}$for the lower side):

$$
\delta=\mathbf{u}^{+}-\mathbf{u}^{-} \Leftrightarrow\left(\begin{array}{c}
\delta_{I I} \\
\delta_{I}
\end{array}\right)=\left(\begin{array}{c}
u^{+}-u^{-} \\
w^{+}-w^{-}
\end{array}\right)
$$

Remark: In the case of the finite element approach, the number of cohesive elements is related to the number of nodes in the mid-plane surface and to the number of layers. In the PGD approach the number of cohesive element in the thickness is only equal to the number of interfaces between layers.

\section{Mathematical formulation for PGD-Cohesive crack problem}

This section focuses on the development of the PGD formulation in conjunction with a bilinear CZM in a two-dimensional domain $\Omega=\Omega_{x} \mathrm{x} \Omega_{z}$. The problem is treated in $2 \mathrm{D}$ using plane strain hypothesis. The boundary of $\Omega$ is noted $\Gamma$. For sake of simplicity and without loss of generality, only two layers with the same thickness $h$ are considered. There is then only one interface between layers. This interface is assumed to be parallel to the $x$ direction as 

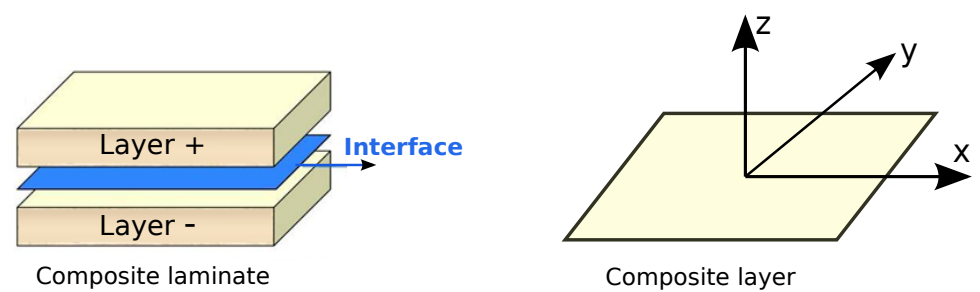

(a) Interface description

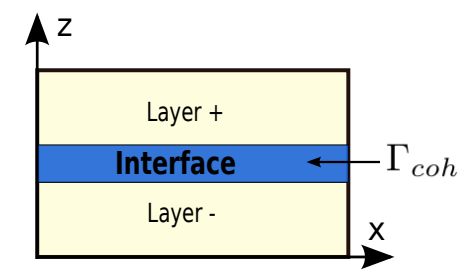

2D Finite element discretization

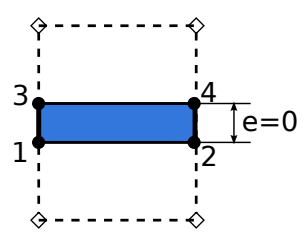

A linear 2D interface cohesive element

(b) FEM - CZM

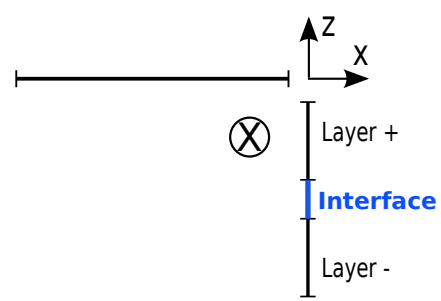

1D/1D PGD discretization

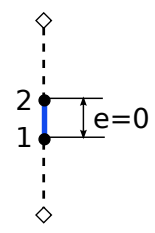

A linear 1D interface cohesive element

(c) PGD - CZM

Figure 2: Definition of cohesive surface. 
represented in Figure 2. The strategy proposed in this paper requires that the cohesive interface is perpendicular to an axis defining the separated decomposition. For example, an oblique crack can't be treated unless the separated decomposition is defined with new coordinates following the crack.

The weak form of the equilibrium equation for a linear elastic material with a cohesive surface $\Gamma_{c o h}$ and a cohesive stress vector $\mathbf{T}_{c o h}$, without body force gives:

$$
\iint_{\Omega} \varepsilon\left(\mathbf{u}^{*}\right) \cdot(\boldsymbol{A} \varepsilon(\mathbf{u})) d \Omega+\int_{\Gamma_{c o h}} \mathbf{T}_{c o h} \delta^{*} d \Gamma=\int_{\Gamma} \mathbf{T}_{e x t} \mathbf{u}^{*} d \Gamma
$$

where $\mathbf{u}^{*}$ and $\delta^{*}$ are the virtual displacement and virtual separation, respectively. $\varepsilon$ is the strain tensor using the matrix form:

$$
\varepsilon=\left(\begin{array}{c}
\varepsilon_{x x} \\
\varepsilon_{z z} \\
2 \varepsilon_{x z}
\end{array}\right)
$$

$\mathbf{T}_{\text {ext }}$ is the external force on the boundary $\Gamma$. $\mathbf{A}$ is a matrix related to the constitutive equation in each layer. For an orthotropic material with plane strain hypothesis $\mathbf{A}$ is defined by:

$$
\boldsymbol{A}^{-1}=\left[\begin{array}{ccc}
\frac{1}{E_{x}} & -\frac{\nu_{x z}}{E_{x}} & 0 \\
-\frac{\nu_{x z}}{E_{x}} & \frac{1}{E_{z}} & 0 \\
0 & 0 & \frac{1}{G_{x z}}
\end{array}\right]
$$

where $E_{x}, E_{z}, \nu_{x z}$ and $G_{x z}$ are the materials parameters (elastic modulus, Poisson ratio and shear modulus). The displacement field $\mathbf{u}(x, z)$ is approximated using the following separated form:

$$
\mathbf{u} \approx \mathbf{u}^{n}(x, z)=\sum_{i=1}^{n} \mathbf{F}_{i}(x) \circ \mathbf{G}_{i}(z) \quad \forall(x, z) \in \Omega
$$

with $\mathbf{F}_{i}(x)=\left(\begin{array}{c}F_{u}^{i}(x) \\ F_{w}^{i}(x)\end{array}\right)$ are functions of the in-plane coordinate and $\mathbf{G}_{i}(z)=\left(\begin{array}{c}G_{u}^{i}(z) \\ G_{w}^{i}(z)\end{array}\right)$ are functions involving the thickness coordinate. ○ denotes the Hadamard product. Eq. 12 is then equivalent to:

$$
\mathbf{u}^{n}=\left(\begin{array}{c}
u_{n} \\
w_{n}
\end{array}\right)=\left(\begin{array}{c}
\sum_{i=1}^{n} F_{u}^{i} G_{u}^{i} \\
\sum_{i=1}^{n} F_{w}^{i} G_{w}^{i}
\end{array}\right)
$$

Then, the separated representation of the strain tensor in Lagrangian description gives:

$$
\varepsilon\left(\mathbf{u}^{n}(x, z)\right)=\sum_{i=1}^{n}\left(\begin{array}{c}
F_{u, x}^{i} G_{u}^{i} \\
F_{w}^{i} G_{w, z}^{i} \\
F_{u}^{i} G_{u, z}^{i}+F_{w, x}^{i} G_{w}^{i}
\end{array}\right)
$$


$f_{, x}$ denotes the derivative of a function $f$ with respect to $x$. It is assumed that the first $n$ modes have been determined at previous iterations. In order to enrich the separated approximation, some new functions $R_{u}(x), S_{u}(x), R_{w}(x)$ and $S_{w}(x)$ have to be determined. The new approximation is then:

$$
\mathbf{u}^{n+1}(x, z)=\mathbf{u}^{n}(x, z)+\left(\begin{array}{c}
R_{u}(x) S_{u}(z) \\
R_{w}(x) S_{w}(z)
\end{array}\right)
$$

That can also be written as:

$$
\begin{aligned}
\mathbf{u}^{n+1}(x, z)= & \mathbf{u}^{n}(x, z)+\left(\begin{array}{c}
R_{u}(x) \\
R_{w}(x)
\end{array}\right) \circ\left(\begin{array}{l}
S_{u}(z) \\
S_{w}(z)
\end{array}\right) \\
& =\mathbf{u}^{n}(x, z)+\mathbf{R}(x) \circ \mathbf{S}(z)
\end{aligned}
$$

The strain derived from Eq. 15 is:

$$
\varepsilon\left(\mathbf{u}^{n+1}(x, z)\right)=\varepsilon\left(\mathbf{u}^{n}(x, z)\right)+\varepsilon(\mathbf{R}(x) \circ \mathbf{S}(z))
$$

And test function $\mathbf{u}^{*}$ is defined from the separated representation:

$$
\begin{aligned}
\mathbf{u}^{*}(x, z) & =\left(\begin{array}{c}
R_{u}^{*}(x) S_{u}(z)+R_{u}(x) S_{u}^{*}(z) \\
R_{w}^{*}(x) S_{w}(z)+R_{w}(x) S_{w}^{*}(z)
\end{array}\right) \\
& =\mathbf{R}^{*}(x) \circ \mathbf{S}(z)+\mathbf{R}(x) \circ \mathbf{S}^{*}(z)
\end{aligned}
$$

The interlaminar normal stress $\sigma_{z z}$ and shear stress $\tau_{x z}$ on the interface are computed from the relative displacement vector defined Eq. 9 using the bilinear cohesive law.

$$
\mathbf{T}_{c o h}=\left(\begin{array}{c}
\sigma_{z z} \\
\tau_{x z}
\end{array}\right)=\left(\begin{array}{c}
\lambda_{I} K_{I} \delta_{I} \\
\lambda_{I I} K_{I I} \delta_{I I}
\end{array}\right)
$$

In pure modes, the values of $\lambda_{j}$ with $j=I, I I$ are computed from Eq. 4.

$$
\lambda_{j}=\left\{\begin{array}{cc}
1 & \delta_{j}<\delta_{c}^{j} \\
\left(1-d_{j}\right) & \delta_{c}^{j} \leq \delta_{j}<\delta_{m}^{j} \\
0 & \delta_{j} \geq \delta_{m}^{j}
\end{array}, \quad j=I, I I\right.
$$

In mixed mode, the damage of the interface is described by $\lambda=\lambda_{I}=\lambda_{I I}$. $\lambda$ is computed from the relations given in section 2.2.

Introducing Eq. 15 and Eq. 18 into the weak form (Eq. 10) it results:

$$
\begin{gathered}
\iint_{\Omega} \varepsilon\left(\mathbf{u}^{*}\right) \cdot[\boldsymbol{A} \varepsilon(\mathbf{R} \circ \mathbf{S})] d \Omega \\
+\int_{\Gamma_{c o h}} \lambda_{I} K_{I}\left(w_{n+1}^{+}-w_{n+1}^{-}\right)\left(w_{n+1}^{+*}-w_{n+1}^{-*}\right) d \Gamma \\
+\int_{\Gamma_{c o h}} \lambda_{I I} K_{I I}\left(u_{n+1}^{+}-u_{n+1}^{-}\right)\left(u_{n+1}^{+*}-u_{n+1}^{-*}\right) d \Gamma \\
\left.=-\iint_{\Omega} \varepsilon\left(\mathbf{u}^{*}\right) \cdot\left[\boldsymbol{A} \varepsilon\left(\mathbf{u}^{n}\right)\right)\right] d \Omega+\int_{\Gamma} \mathbf{T}_{e x t} \mathbf{u}^{*} d \Gamma
\end{gathered}
$$


The cohesive surface is normal to the thickness so that $\Gamma_{c o h} \equiv \Omega_{x}$. The initial positions of the two faces of the cohesive zone are defined by their coordinates on $\Omega_{z}$ denoted $z^{+}$and $z^{-}$for all $x \in \Omega_{x}$. After discretization, $z^{+}$and $z^{-}$define the coordinates of two nodes on $\Omega_{z}$ that may be initially at the same position.

It comes using Eq. 15:

$$
\left\{\begin{array}{c}
u_{n+1}^{+}-u_{n+1}^{-}=R_{u}(x)\left(S_{u}\left(z^{+}\right)-S_{u}\left(z^{-}\right)\right)+\sum_{i=1}^{n} F_{u}^{i}(x)\left(G_{u}^{i}\left(z^{+}\right)-G_{u}^{i}\left(z^{-}\right)\right) \\
w_{n+1}^{+}-w_{n+1}^{-}=R_{w}(x)\left(S_{w}\left(z^{+}\right)-S_{w}\left(z^{-}\right)\right)+\sum_{i=1}^{n} F_{w}^{i}(x)\left(G_{w}\left(z^{+}\right)-G_{w}\left(z^{-}\right)\right)
\end{array}\right.
$$

Finding the couple of functions $(\mathbf{R}, \mathbf{S})$ is a highly non linear problem. For that purpose, an alternating directions strategy is used. It proceeds as follows: At each iteration a single function $\mathbf{R}$ or $\mathbf{S}$ is computed alternately assuming the other known. This procedure continues until convergence. So, there are two steps:

\section{1. finding $\mathbf{R}$ assuming $\mathbf{S}$}

\section{2. finding $\mathbf{S}$ assuming $\mathbf{R}$}

At the beginning of the procedure, the functions $\mathbf{R}$ and $\mathbf{S}$ are initialized with some arbitrary functions. In practical, the initialization values have a weak impact on the convergence. Random functions coherent with boundary conditions are used in this work.

Only the first step is described in the following because the second step is very similar.

Then from now on, $\mathbf{R}(x)$ is assumed known and $\mathbf{S}(z)$ is being looked for. The test function then becomes:

$$
\mathbf{u}^{*}(x, z)=\left(\begin{array}{c}
R_{u}(x) S_{u}^{*}(z) \\
R_{w}(x) S_{w}^{*}(z)
\end{array}\right)=\mathbf{R}(x) \circ \mathbf{S}^{*}(z)
$$

Implying the strain tensor:

$$
\varepsilon\left(\mathbf{u}^{n *}(x, z)\right)=\varepsilon\left(\mathbf{R}(x) \circ \mathbf{S}^{*}(z)\right)=\sum_{i=1}^{n}\left(\begin{array}{c}
R_{u, x} S_{u}^{*} \\
R_{w} S_{w, z}^{*} \\
R_{u} S_{u, z}^{*}+R_{w, x} S_{w}^{*}
\end{array}\right)
$$


The weak form becomes:

$$
\begin{gathered}
\iint_{\Omega} \varepsilon\left(\mathbf{R} \circ \mathbf{S}^{*}\right) \cdot[\boldsymbol{A} \varepsilon(\mathbf{R} \circ \mathbf{S})] d \Omega \\
+\int_{\Gamma_{c o h}} \lambda_{I} K_{I}\left[\left(\sum_{i=1}^{n} F_{w}^{i}(x) G_{w}\left(z^{+}\right)+R_{w}(x) S_{w}\left(z^{+}\right)\right)\right. \\
\left.-\left(\sum_{i=1}^{n} F_{w}^{i}(x) G_{w}^{i}\left(z^{-}\right)+R_{w}(x) S_{w}\left(z^{-}\right)\right)\right]\left[R_{w}(x) S_{w}^{*}\left(z^{+}\right)-R_{w}(x) S_{w}^{*}\left(z^{-}\right)\right] d \Gamma \\
+\int_{\Gamma_{c o h}} \lambda_{I I} K_{I I}\left[\left(\left(\sum_{i=1}^{n} F_{u}^{i}(x) G_{u}^{i}\left(z^{+}\right)+R_{u}(x) S_{u}\left(z^{+}\right)\right)\right.\right. \\
\left.-\left(\sum_{i=1}^{n} F_{u}^{i}(x) G_{u}^{i}\left(z^{+}\right)+R_{u}(x) S_{u}\left(z^{+}\right)\right)\right]\left[R_{u}(x) S_{u}^{*}\left(z^{+}\right)-R_{u}(x) S_{u}^{*}\left(z^{-}\right)\right] d \Gamma \\
=-\iint_{\Omega} \varepsilon\left(\mathbf{R} \circ \mathbf{S}^{*}\right) \cdot\left[\boldsymbol{A} \varepsilon\left(\mathbf{u}^{n}\right)\right] d \Omega+\int_{\Gamma} \mathbf{T}_{e x t}\left(\mathbf{R} \circ \mathbf{S}^{*}\right) d \Gamma
\end{gathered}
$$

The following coefficients are defined:

$$
\left\{\begin{array}{c}
\alpha_{j}^{k}=\int_{\Gamma_{c o h}} \lambda_{j} K_{j} R_{k}(x) \sum_{i=1}^{n} F_{k}^{i}(x) G_{k}^{i}\left(z^{+}\right) d \Gamma \\
\beta_{j}^{k}=\int_{\Gamma_{c o h}} \lambda_{j} K_{j}\left(R_{k}(x)\right)^{2} d \Gamma \\
\gamma_{j}^{k}=\int_{\Gamma_{c o h}} \lambda_{j} K_{j} R_{k}(x) \sum_{i=1}^{n} F_{k}^{i}(x) G_{k}^{i}\left(z^{-}\right) d \Gamma
\end{array} \quad j=(I, I I) ; k=(u, w)\right.
$$

These coefficient can be calculated numerically with $\Gamma_{c o h} \equiv \Omega_{x}$. Using the previous notations, Eq. 24 becomes:

$$
\begin{gathered}
\iint_{\Omega} \varepsilon\left(\mathbf{R} \circ \mathbf{S}^{*}\right) \cdot[\boldsymbol{A} \varepsilon(\mathbf{R} \circ \mathbf{S})] d \Omega \\
+\alpha_{I}^{w} \cdot S_{w}^{*}\left(z^{+}\right)+\beta_{I}^{w} \cdot S_{w}^{*}\left(z^{+}\right) S_{w}\left(z^{+}\right)-\gamma_{I}^{w} \cdot S_{w}^{*}\left(z^{+}\right)-\beta_{I}^{w} \cdot S_{w}^{*}\left(z^{+}\right) S_{w}\left(z^{-}\right) \\
-\alpha_{I}^{w} \cdot S_{w}^{*}\left(z^{-}\right)-\beta_{I}^{w} \cdot S_{w}^{*}\left(z^{-}\right) S_{w}\left(z^{+}\right)+\gamma_{I}^{w} \cdot S_{w}^{*}\left(z^{-}\right)+\beta_{I}^{w} \cdot S_{w}^{*}\left(z^{-}\right) S_{w}\left(z^{-}\right) \\
+\alpha_{I I}^{u} \cdot S_{u}^{*}\left(z^{+}\right)+\beta_{I I}^{u} \cdot S_{u}^{*}\left(z^{+}\right) S_{u}\left(z^{+}\right)-\gamma_{I I}^{u} \cdot S_{u}^{*}\left(z^{+}\right)-\beta_{I I}^{u} \cdot S_{u}^{*}\left(z^{+}\right) S_{u}\left(z^{-}\right) \\
-\alpha_{I I}^{u} \cdot S_{u}^{*}\left(z^{-}\right)-\beta_{I I}^{u} \cdot S_{u}^{*}\left(z^{-}\right) S_{u}\left(z^{+}\right)+\gamma_{I I}^{u} \cdot S_{u}^{*}\left(z^{-}\right)+\beta_{I I}^{u} \cdot S_{u}^{*}\left(z^{-}\right) S_{u}\left(z^{-}\right) \\
\quad=-\iint_{\Omega} \varepsilon\left(\mathbf{R} \circ \mathbf{S}^{*}\right) \cdot\left[\boldsymbol{A} \varepsilon\left(\mathbf{u}^{n}\right)\right] d \Omega+\int_{\Gamma} \mathbf{T}_{e x t}\left(\mathbf{R} \circ \mathbf{S}^{*}\right) d \Gamma
\end{gathered}
$$

At this point, a classical PGD solver can be used. The terms $\iint_{\Omega} \varepsilon(\mathbf{R} \circ$ $\left.\mathbf{S}^{*}\right) .[\boldsymbol{A} \varepsilon(\mathbf{R} \circ \mathbf{S})] d \Omega$ and $\iint_{\Omega} \varepsilon\left(\mathbf{R} \circ \mathbf{S}^{*}\right) .\left[\boldsymbol{A} \varepsilon\left(\mathbf{u}^{n}\right)\right] d \Omega$ can be developed as a sum of simple integrals using the expression of $\varepsilon$ and A. These integrals on $\Omega$ can be separated as a product of integrals on $\Omega_{x}$ and on $\Omega_{z}$. The integrals on $\Omega_{x}$ can be calculated numerically because all functions defined on $\Omega_{x}$ are known. It remains a problem on $\Omega_{z}$ that can be solved using the finite element method.

For more details about the PGD resolution technique, the reader can refer to $[10]$.

\section{Numerical simulations}

Three fracture mechanics tests were selected to validate the proposed modeling for two-dimensional fracture problems. Each test is related to a particular mode of propagation of the crack. The first test carried out was the DCB test, 


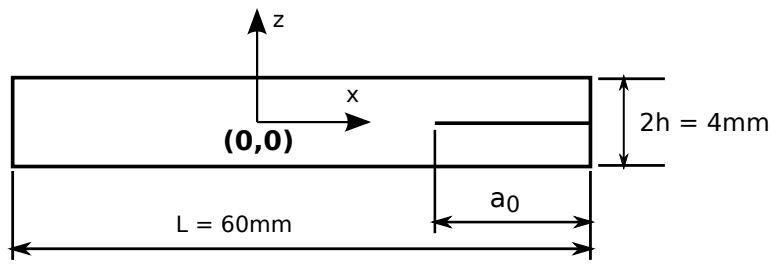

Figure 3: specimen geometrical dimensions.

in which the delamination happens mainly in a mode I. The second was the ELS test, related to the failure mode II. The last one was the MMF test for mixed mode damage.

Numerical simulations performed using the PGD are compared with results of classical FEM implementation using the same set of parameters. The aim is to validate the PGD approach and to evaluate its response with respect to constitutive laws, damage formulations and cohesive zone key parameters. In the two cases a static simulation is performed which avoids the use of an explicit scheme leading in a very severe restriction on the time step. In the FEM, a fixed point algorithm is used to treat the non linearity coming from Eq. 18. The PGD is by nature a non-linear solver. The linearization of the operators required can be performed at each iteration of the PGD. There are many ways to do this. The following strategy is chosen:

1. The operators related to the cohesive zones are linearized using a fixed value of $\lambda(\lambda=1$ at the first iteration).

2. A new term of the PGD expansion defined in Eq. 12 is computed with the linearized operators.

3. The partial PGD solution is used to determine the values of the displacement discontinuity $\delta$ along the cohesive zone. Then, the cohesive law gives new values for $\lambda$.

4. The PGD residual error is computed. If the convergence is not reached, return to 1 .

\subsection{Material properties}

The specimen geometry used in this work is shown in Figure 3. The properties of the material (a unidirectional carbon/epoxy composite) and the ones of the cohesive interface are listed in Table 1. The upper and lower layers (unidirectional layers) of the specimen are modeled with a transverse isotropic constitutive law.

The element size for the solid and the cohesive elements, is the same for all models and is equal to $0.2 \mathrm{~mm}$. The interface element stiffnesses $\left(K_{I}\right.$ and $\left.K_{I I}\right)$ are chosen to get a good compromise between convergence calculation, computation time and elastic properties of the laminate [29]. The computational cost strongly depends on the initial stiffness values. As a matter of fact, the 


\begin{tabular}{|c|c|c|c|}
\hline \multicolumn{2}{|c|}{ Material properties } & \multicolumn{2}{c|}{ Interfacial properties } \\
\hline \hline$E_{z}(M P a)$ & 11873 & $G_{I c}(N / m m)$ & 0.3 \\
\hline$E_{x}(M P a)$ & 157380 & $G_{I I c}(N / m m)$ & 1.6 \\
\hline$G_{x z}(M P a)$ & 5051 & $\sigma_{c}(M P a)$ & 60 \\
\hline$\nu_{x z}$ & 0.31 & $\tau_{c}(M P a)$ & 139 \\
\hline & & $K_{3}\left(N / m^{3}\right)$ & $1.10^{4}$ \\
\hline & & $K_{1}\left(N / m^{3}\right)$ & $5.10^{4}$ \\
\hline
\end{tabular}

Table 1: Material properties for carbon/epoxy.

CPU time increases when $K_{I}$ and $K_{I I}$ are raised. For a high value of the failure stresses $\left(\sigma_{c}\right.$ and $\left.\tau_{c}\right)$, convergence problems may occur. Those problems are due to a significant drop in the slope of the interface stiffness after the failure stresses are reached.

Since $\tau_{c}$ has a large influence on the interface behaviour, we chose to link it to $\sigma_{c}$ according to the following dependence, already noted in [30]:

$$
\tau_{c}=\sigma_{c} \sqrt{\frac{G_{I I c}}{G_{I c}}}
$$

The $\frac{\delta_{c}^{i}}{\widehat{\delta}_{m}^{i}}$ ratio $(i=I, I I)$ is also an important factor to validate the Crisfield law [31]. We found that, for certain values of this ratio, the critical energy release rate required to propagate the crack was less than imposed in our calculation. This observation was already made by Vandellos et al. [31] who varied the $\frac{\delta_{c}^{i}}{\delta_{m}^{i}}$ ratio in order to get the correct rate. We had applied the same method, which enabled us to assume a consistent value for $G_{I c}$ and $G_{I I c}$. It is those values that are presented in Table 1.

In what follows, we describe in details the boundary conditions of each test.

\subsection{DCB test}

The DCB test, with boundary conditions and loadings are shown in Figure 4. This test considers a composite laminate with an initial delamination crack $a_{0}$. It is an opening mode test: the initial crack propagation is forced by applying two opposite forces $(P)$ or displacements that pull the upper and lower parts of the specimen. The length of the initial crack was $a_{0}=20 \mathrm{~mm}$. The analytical solutions based on the beam theory [32] for the compliance $(C)$ and on the fracture mechanics for the propagation of the delamination are:

$$
\begin{gathered}
C=\frac{\delta}{P}=\frac{8 a^{3}}{b E_{x} h^{3}} \\
G_{I}=\frac{1}{2 b} P^{2} \frac{d C}{d a}=\frac{12 P^{2} a^{2}}{b^{2} E_{x} h^{3}}
\end{gathered}
$$

where $E_{x}$ is the longitudinal modulus of the material, $h$ is the half-thickness, $b$ the specimen width, $a$ the instantaneous crack length and $P$ the reaction force. 

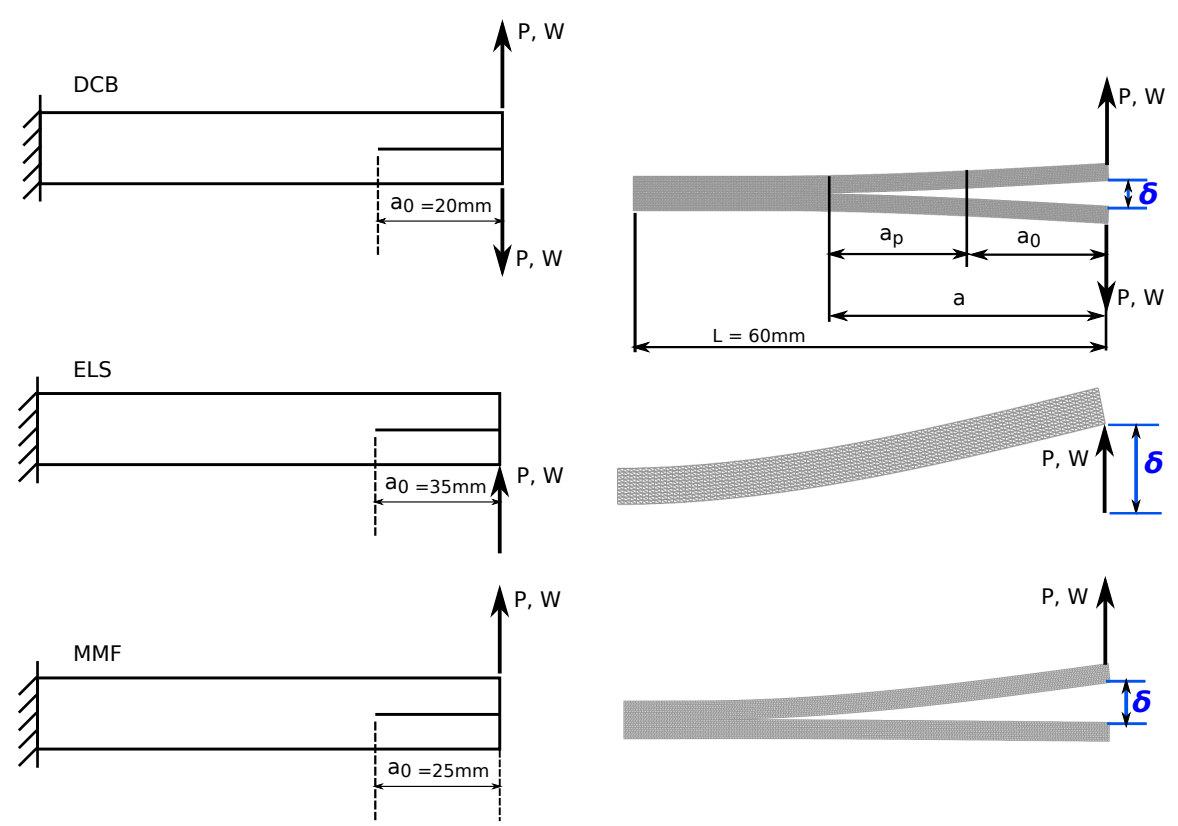

Figure 4: Configurations of tests.

The energy $G_{I}$ can also be expressed as a function of the relatives separation (ס) according to:

$$
G_{I}=\frac{3 E_{x} h^{3} \delta^{2}}{16 a^{4}}
$$

\subsection{ELS test}

The ELS test is a simple flexural test used in pre-cracked specimen with a fixed length $L$ and a fixed crack length $a_{0}[33,34]$. Since $L=60 \mathrm{~mm}$, we select $a_{0}=35 \mathrm{~mm}$ to verify the condition $a_{0} / L>0.55$ necessary to have a stable crack growth. This test produces a failure in mode II due the shear stress between the two cohesive surfaces. According to the beam theory approach and the LEFM, the compliance and the analytical energy release rate for the ELS test can be determined as:

$$
\begin{gathered}
C=\frac{\delta}{P}=\frac{3 a^{3}+L^{3}}{2 b E_{x} h^{3}} \\
G_{I I}=\frac{9 P^{2} a^{2}}{4 b^{2} E_{x} h^{3}}
\end{gathered}
$$

Combining both equations gives:

$$
G_{I I}=\frac{9 \delta^{2} E_{x} h^{3} a^{2}}{\left(3 a^{3}+L^{3}\right)^{2}}
$$




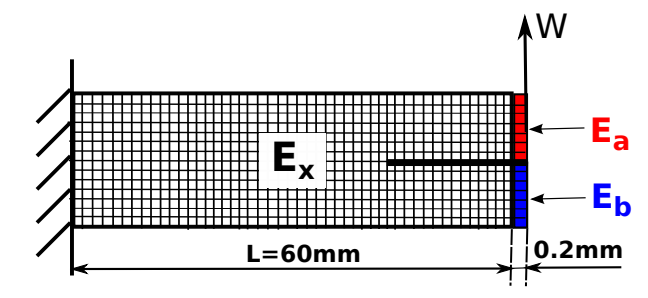

Figure 5: Implementation of mixed boundary conditions in PGD. $E_{x}$ is the longitudinal elastic modulus, the new elements (in colors) are incorporated at the surface where mixed boundary conditions are imposed.

\section{4. $M M F$ test}

The MMF is a mixed-mode I/II test [35] that is depicted in Figure 4. It is also known as mixed-mode end load split test (MMELS). The force is applied on the upper arm in the direction of the thickness while the lower arm remains unloaded. To ensure the mixed mode, the length of the precrack must respect the condition $a_{0} / L>0.41$. The analytical expressions for the compliance and for the mode I and mode II energy release rates related to the MMF test can be given as:

$$
\begin{aligned}
C & =\frac{7 a^{3}+L^{3}}{2 b E_{x} h^{3}} \\
G_{I} & =\frac{3 P^{2} a^{2}}{b^{2} E_{x} h^{3}} \\
G_{I I} & =\frac{9 P^{2} a^{2}}{4 b^{2} E_{x} h^{3}}
\end{aligned}
$$

If the thickness of the two layers are equal, the $G_{I I} / G_{I}$ ratio is $\frac{3}{4}$. The analytical total energy release is given by:

$$
G_{T}=G_{I}+G_{I I}=\frac{21 E_{x} h^{3} a^{2} \delta^{2}}{\left(7 a^{3}+L^{3}\right)^{2}}
$$

Using Eq. 7, the critical value of the total energy release rate under mixed mode loading can be expressed as follows:

$$
G_{T c}=\frac{\left(1+\beta^{2}\right) G_{I c} G_{I I c}}{\left[\left(G_{I I c}\right)^{2}+\left(\beta^{2} G_{I c}\right)^{2}\right]^{1 / 2}}
$$

With:

$$
\beta^{2}=\frac{G_{I I}}{G_{I}}
$$

Definition of mixed boundary conditions with the PGD

PGD does not enable direct introduction of mixed boundary conditions as required in the MMF test. Several methods have been proposed to incorporate such boundary conditions like penalization method and Lagrangian method [36]. In our case, these two methods lead to convergence problems. Therefore, a third method more efficient was designed in this paper. It consists in the addition 


\begin{tabular}{|c|c|c|c|}
\cline { 2 - 4 } \multicolumn{1}{c|}{} & DCB test & ELS test & MMF test \\
\hline Length (mm) & 4.6 & 2.2 & 1.8 \\
\hline \hline Number of Elements & 23 & 11 & 9 \\
\hline
\end{tabular}

Table 2: Quantification of the simulated process zone length using the PGD method.

of some elements which are located at the place where the mixed boundary conditions are imposed. Figure 5 represents the introduction of such virtual elements. The added elements which undergo imposed displacement (the ones situated in the upper part of the specimen) are defined with an elastic modulus $E_{a}$ equal to $E_{x}$ or higher. The other elements corresponding to a free surface (situated in the lower part of the specimen) are defined with an elastic modulus $E_{b}$ equal to zero. In that way, a uniform displacement can be enforce on the right side. The load is transmitted only on the elements situated in the upper part. There is no numerical difficulties with $E_{b}=0$ because the problem is solved in the context of the PGD. Only 1D problems are treated in practice with no numerical problems.

\subsection{Tests results}

The solution obtained with the PGD gives the functions $\mathbf{F}_{i}$ and $\mathbf{G}_{i}$ from which the displacement field is built (using Eq. 12). These functions are depicted for the DCB test in Figure 17. In all the test cases, the global forcedisplacement curves are shown in Figure 7. Two stages can be obtained: $(i)$ linear elastic response before damage is initiated and, $(i i)$ crack propagation. In the linear part, when the opening displacement increases, the load increases as well. On the contrary, the load decreases during the crack propagation. A slight nonlinear behavior may be observed before the maximum load point, especially in the MMF test. A very good agreement is observed between PGD and finite element simulations. The analytical model is based on the beam theory and underestimates the compliance and the strain energy release rate.

For these simulations, Figure 8 shows the damage variable along the crack path for an imposed displacement. The process zone was defined as the zone in which the damage variable is strictly between 0 and 1, as shown in Figure 9. The length of the process zone is given in Table 2, for a common mesh size of $0.2 \mathrm{~mm}$. In these simulations it is mandatory to obtain a number of element in the process zone which is larger than a critical number ( 3 or 5 elements according to [29]). In our simulations, we found sufficient number of elements in the process zone, as mentioned in Table 2.

The evolution of the local interface separations along the crack path are shown in Figure 10. The relative separation decreased from the edge on which the displacement is applied and tends towards zero in the undamaged zone after the process zone. This figure shows that for an imposed displacement equal to $1.5,5$ and $4 \mathrm{~mm}$ in the case of DCB, ELS and MMF tests respectively, the preexisting crack was propagated by $a_{p}$ equal to $22,20.2$ and $26.8 \mathrm{~mm}$. In all cases, a good accordance between the PGD and FEM is obtained at the interface. 

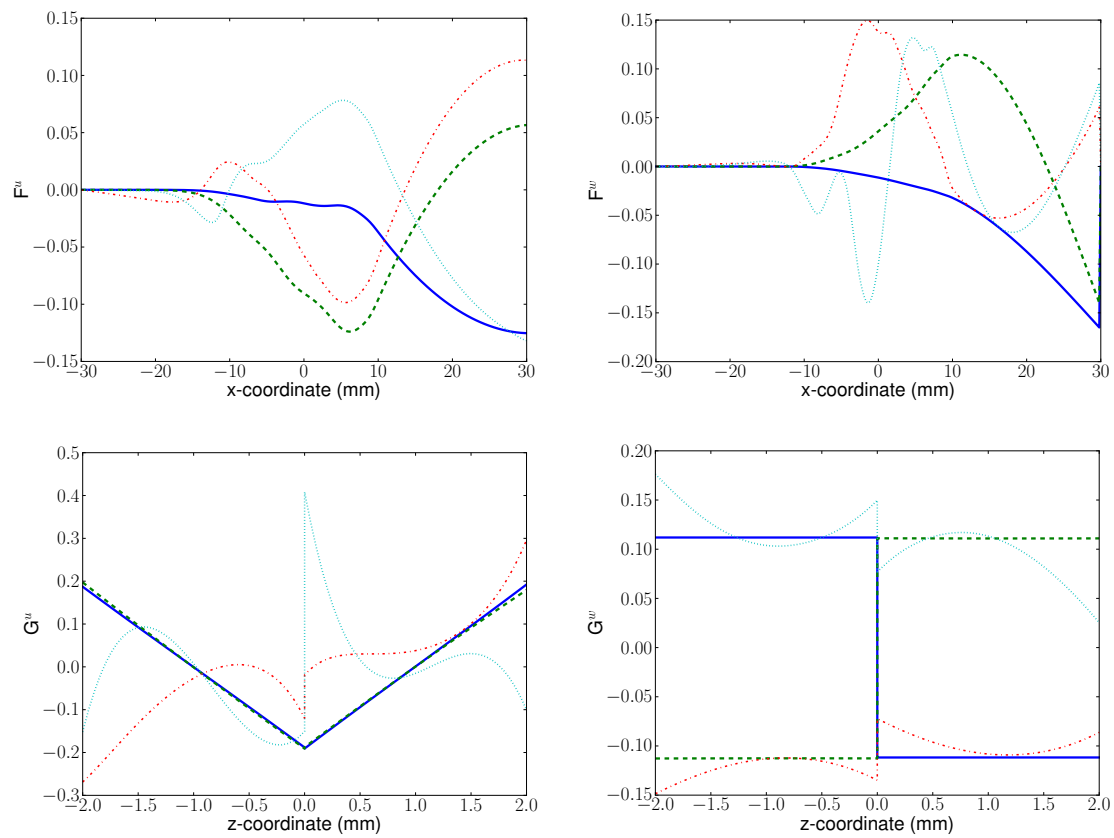

Figure 6: Functions $\mathbf{F}_{i}$ and $\mathbf{G}_{i}$ in the separated representation of the displacement field.

\begin{tabular}{|c|c|c|c|}
\hline Mean relative errors (\%) & DCB test & ELS test & MMF test \\
\hline$\sigma_{x x}$ stresses & 0.3 & 0.2 & 0.3 \\
\hline$\sigma_{z z}$ stresses & 1.6 & - & 2 \\
\hline$\sigma_{x z}$ stresses & - & 3 & 3 \\
\hline
\end{tabular}

Table 3: Mean relative error.

The $\sigma_{x x}$ and $\sigma_{z z}$ stress distributions are plotted for the three fracture tests in Figs. 11, 12 and 13. The PGD approach and the classical FEM approach gives here again very similar results. The mean relative errors of the stress between the PGD and the FEM for each tests are mentioned in Table 3.

A tension zone and a compressive zone are observed near the crack tip in the stress distributions of the DCB test. The compression is generated by the bending moment applied by the upper and low beams of the specimen [37]. Four stages were isolated in Figure 7: (i) " $\mathrm{A}$ " the elastic region, (ii) "B" damage initiation, (iii) "C" crack growth and (iiii) "D" advanced growth of the crack. The cohesive stresses at the different stages are depicted in Figs. 14 and 15 for the DCB and ELS test. In the DCB test, the tension and compressive zones mentioned above are present at all stages. The cohesive stress behind the crack tip (tensile stress) follow the evolution of Figure 7 (case of DCB test). The compressive stresses increase continuously. Figure 12 and Figure 13 represent the stress in the specimen for ELS and DCB tests. For the $\sigma_{x x}$ component, it 


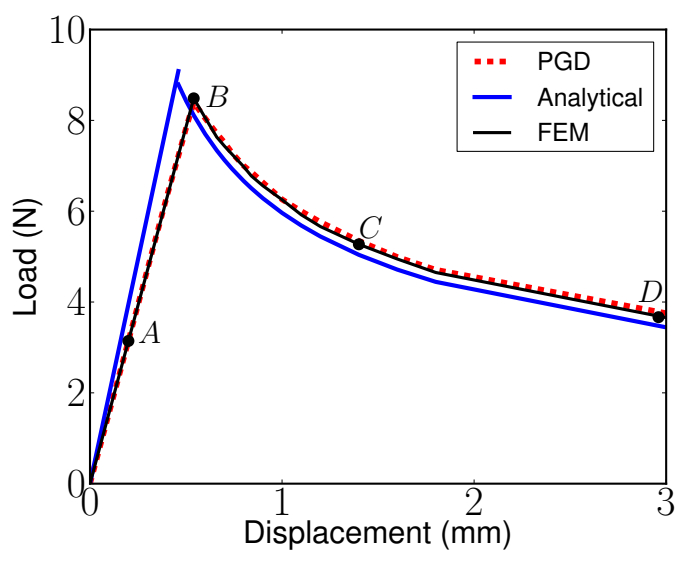

(a)

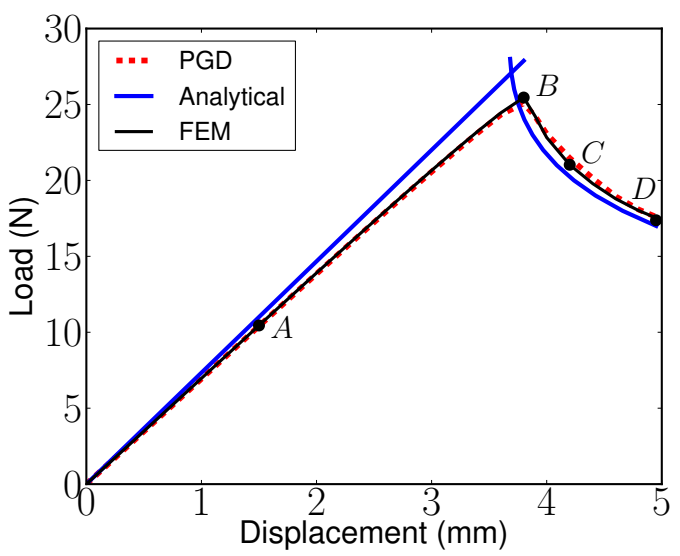

(b)

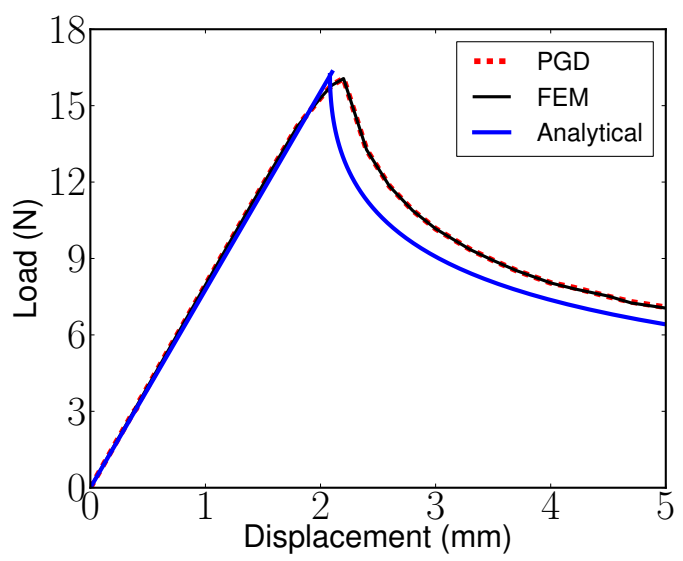

(c)

Figure 7: Force vs. displacement curves for: (a) DCB test, (b) ELS test and (c) MMF test. 
is possible to see that the lower surfaces of the beams are subject to a traction and the upper surfaces are in compression due to the flexural loading.

The two-dimensional PGD model described above gives a good predictions of the delamination compared to FEM in all the configuration and with small computation time. The computational time using the PGD was decrease by a factor of 4 .

\section{6. $3 D$ simulation of a DCB test using the $P G D$ approach}

The main advantage of the PGD approach in comparison with the FEM approach is the reduction of the computational time. Previous 2D simulations showed that PGD is about 4 times faster than FEM, and the agreement between FEM and PGD is very good. Another asset is the easy insertion of the cohesive elements. In FEM-CZM a whole mesh refinement is required when inserting cohesive elements.

A 3D DCB test case is realized to focus on the efficiency of PGD when increasing the number of nodes in the mesh. To do that, the same specimen geometry as shown in Figure 3 is used, together with the same precrack length as in the previous 2D DCB test. The specimen width is equal to $20 \mathrm{~mm}$. The properties of the material are the same as in Table 1.

The $3 \mathrm{D}$ mesh is separated into a $2 \mathrm{D}$ and a $1 \mathrm{D}$ meshes as represented in Figure 16.

In this case, the displacement field denoted $u(x, y, z)$ is approximated using the separated form:

$$
\mathbf{u} \approx \mathbf{u}^{n}(x, y, z)=\sum_{i=1}^{n} \mathbf{F}_{i}(x, y) \circ \mathbf{G}_{i}(z) \quad \forall(x, y, z) \in \Omega
$$

with $\mathbf{F}_{i}(x, y)=\left(\begin{array}{c}F_{u}^{i}(x, y) \\ F_{v}^{i}(x, y) \\ F_{w}^{i}(x, y)\end{array}\right)$ are functions of the mid-plane coordinate and $\mathbf{G}_{i}(z)=\left(\begin{array}{c}G_{u}^{i}(z) \\ G_{v}^{i}(z) \\ G_{w}^{i}(z)\end{array}\right)$ are functions involving the thickness coordinate. The functions $F_{w}^{i}$ and $G_{w}^{i}$ for $i=[1,2]$ are depicted in Figure 17 .

The deformed shape and the longitudinal stress distribution $\left(\sigma_{x x}\right)$ for an imposed displacement equal to $8 \mathrm{~mm}$ are shown in Figure 18. The cohesive surface at several iterations is shown in Figure 19. In this figure, the blue color indicates the undamaged zone, the red color indicates the damaged zone and the process zone is the small part between them. The initial precrack front shape is straight. It is possible to see that the crack initiates at the center-width of specimen. As the crack propagates, the crack front shape becomes slightly convex.

This simulation was performed with 20000 nodes in the $2 \mathrm{D}$ mesh and with 30 nodes in the $1 \mathrm{D}$ mesh (thickness). In $3 \mathrm{D}$, that represents a total of $1.8 \times 10^{6}$ degrees of freedom. The PGD algorithm enabled running the simulation on a simple laptop in less than 15 minutes. This represents an enormous gain of 


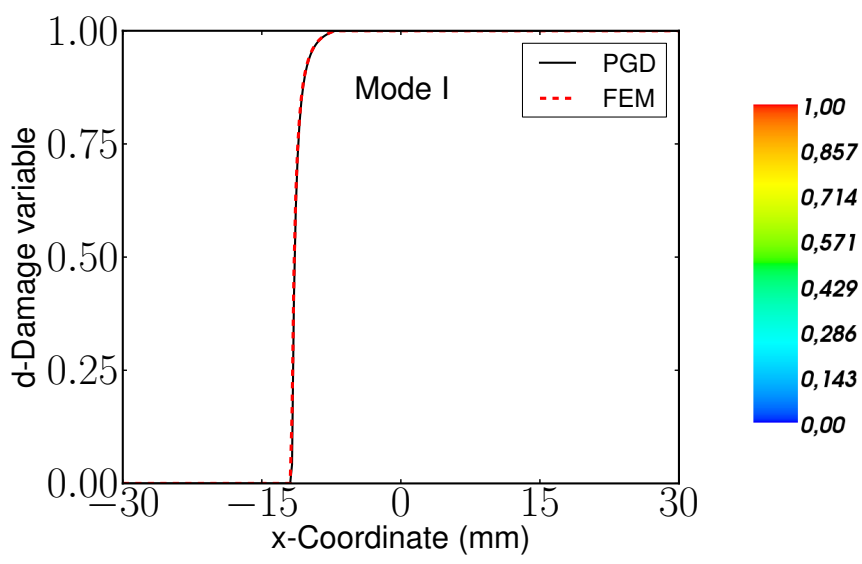

(a)

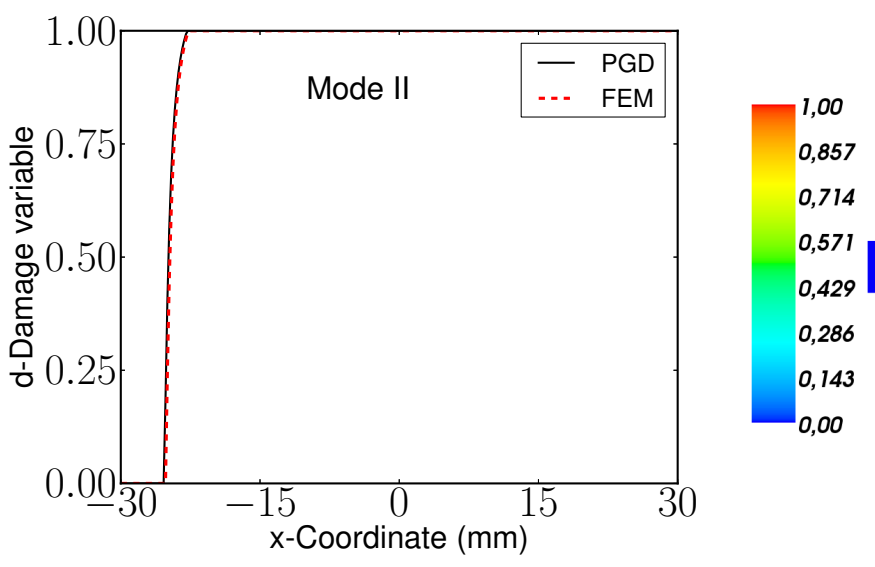

(b)

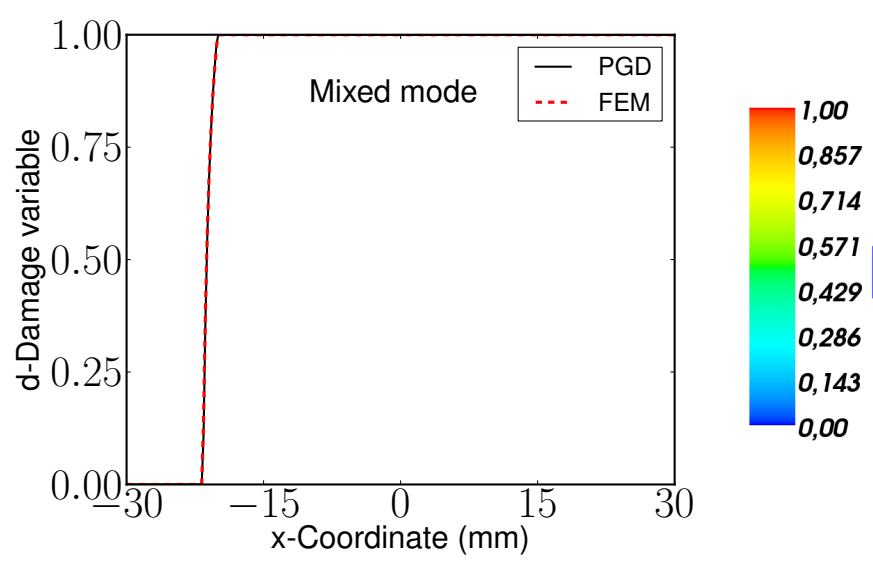

(c)

Figure 8: Damage variable evolution along the crack path for an imposed displacement: (a) DCB test, (b) ELS test and (c) MMF test. 


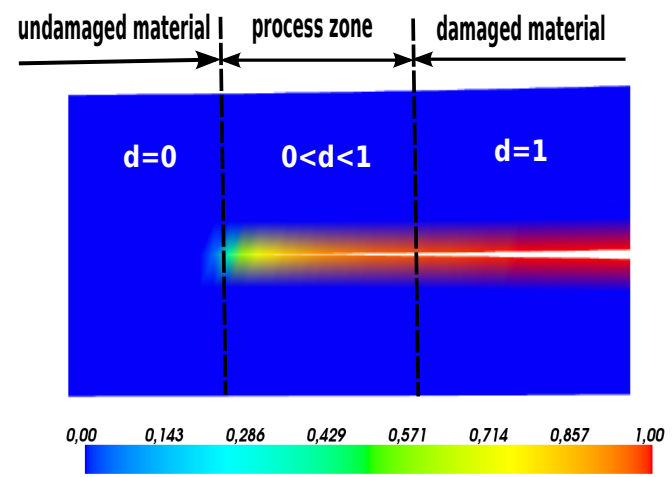

Figure 9: Crack tip in the case of DCB test.

time when compared to classical 3D FEM simulations with comparable mesh refinement.

\section{Conclusions and perspectives}

In this work, an approach based on the PGD has been proposed to simulate delamination in composite laminates. Three classical tests (DCB, ELS and MMF) have been modeled using PGD and FEM as a reference. These two methods have been implemented in conjunction with CZM to represent delamination in different fracture modes (two pure modes, mixed mode). For all modes, close agreements are found between PGD, FEM and analytical solutions. This shows that PGD can be used as an alternative to overcome the computational drawbacks of FEM such as the rapid increase in the number of degrees of freedom, the large computational time and the storage limitation. PGD was found appropriate to capture physical phenomena which occurs at the interface between layers. Finally, reduction of the number of interface elements was achieved by the PGD-CZM new discretization strategy, which minimizes modeling complexity.

This work has focused on static problems. The strategy could be now developed for dynamical transient applications. In the case of explicit or implicit time integration scheme, a work could be done on the actualization of the separated approximation given by the PGD (instead of recomputing the entire approximation).

[1] A. Leski. Implementation of the virtual crack closure technique in engineering fe calculations. Finite Elements in Analysis and Design, 43(3):261-268, January 2007.

[2] P.F. Liua, S.J. Houa, J.K. Chua, X.Y. Hub, C.L. Zhoua, Y.L. Liua, J.Y. Zhenga, A. Zhaoa, and L. Yana. Finite element analysis of postbuckling and 
Local relative separations

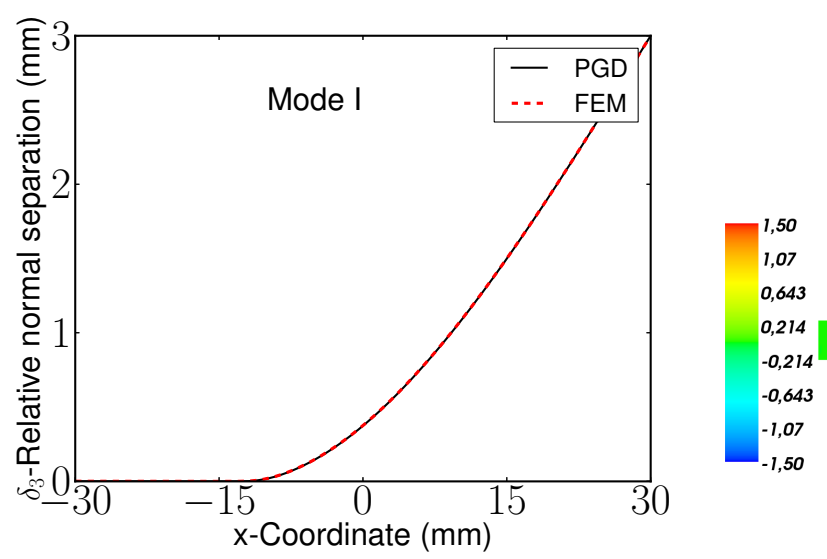

(a)

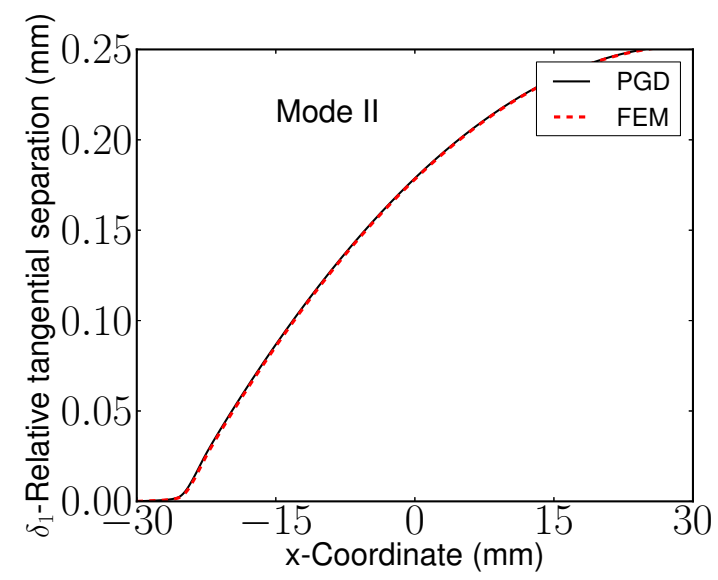

(b)

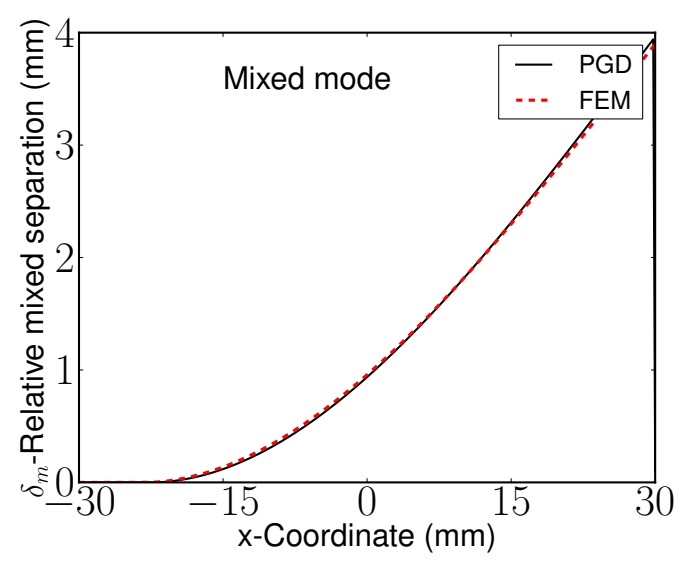

(c)
Global normal displacements

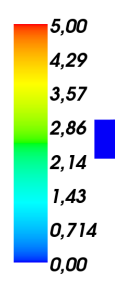

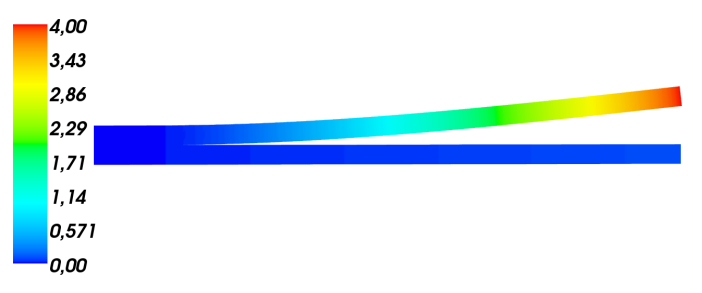

Figure 10: Interface separations evolution along the crack path: (a) DCB test, (b) ELS test and (c) MMF test. 
FEM

PGD

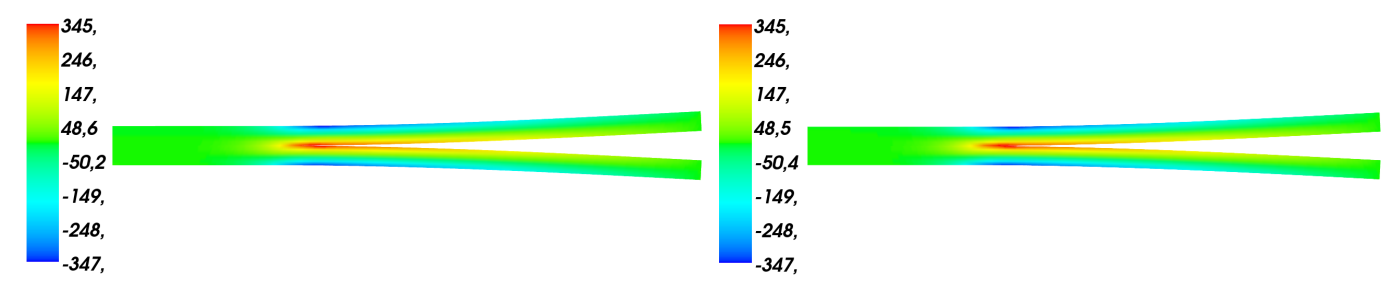

(a) Stress $\sigma_{x x}$

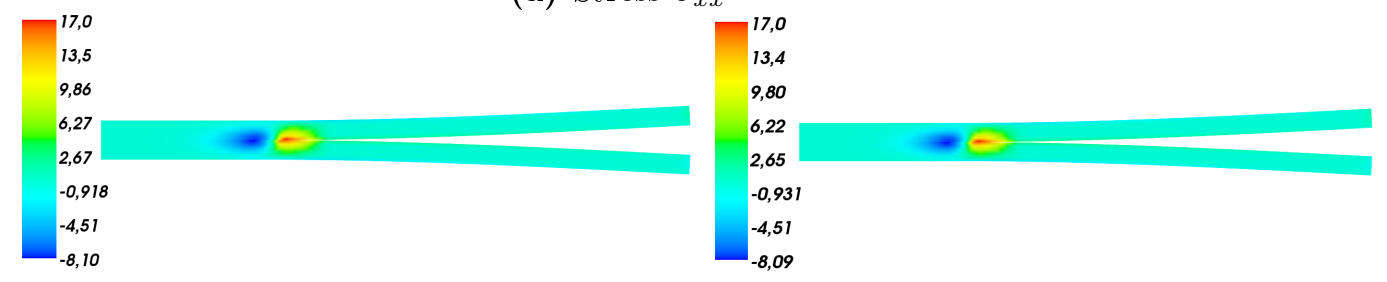

(b) Stress $\sigma_{z z}$

Figure 11: The stress distributions in the longitudinal and thickness direction for the DCB specimen: (a) Stress $\sigma_{x x}$, (b) Stress $\sigma_{z z}$.

delamination of composite laminates using virtual crack closure technique. Composite Structures, 93(6):1549-1560, May 2011.

[3] E.F. Rybicki and M.F. Kanninen. A finite element calculation of stress intensity factors by a modified crack closure integral. Engineering Fracture Mechanics, 9(4):931-938, 1977.

[4] D. Xie, B. Sherrill, and Jr. Biggers. Progressive crack growth analysis using interface element based on the virtual crack closure technique. Finite Elements in Analysis and Design, 42(11):977-984, July 2006.

[5] D.S. Dugdale. Yielding of steel sheets containing slits. Journal of the Mechanics and Physics of Solids, 8(2):100-104, May 1960.

[6] G.I. Barenblatt. The mathematical theory of equilibrium cracks in brittle fracture. Advances in Applied Mechanics, 7:55-129, 1962.

[7] C. Balzani and W. Wagner. An interface element for the simulation of delamination in unidirectional fiber-reinforced composite laminates. Engineering Fracture Mechanics, 75(9):2597-2615, June 2008.

[8] R.T. Tenchev and B.G. Falzon. A pseudo-transient solution strategy for the analysis of delamination by means of interface elements. Finite Elements in Analysis and Design, 42(8-9):698-708, May 2006. 
FEM

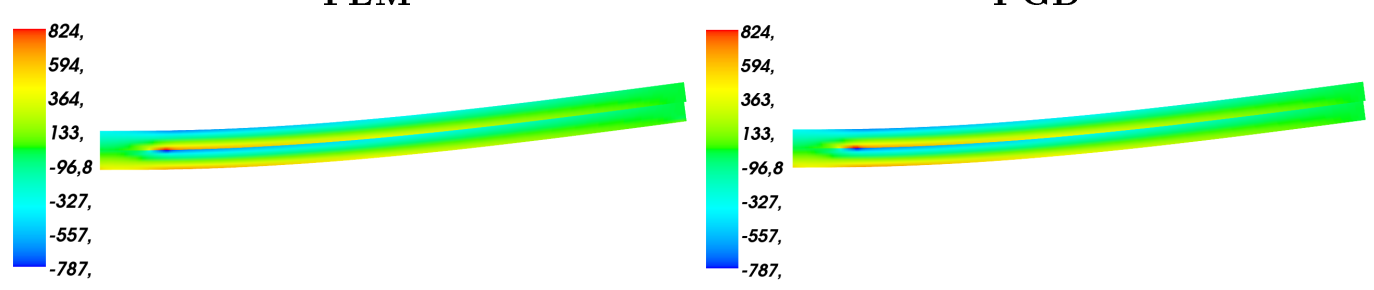

(a) Stress $\sigma_{x x}$

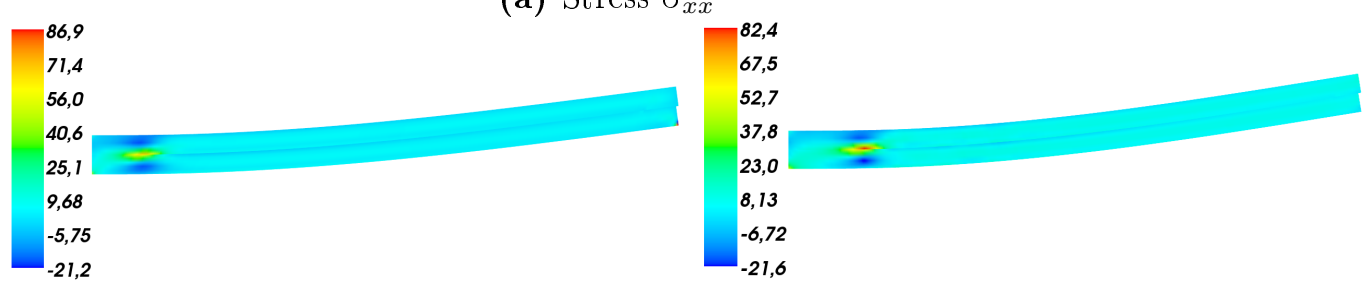

(b) Stress $\sigma_{x z}$

Figure 12: The distribution of longitudinal and shear stresses for the ELS specimen: (a) Stress $\sigma_{x x},(\mathrm{~b})$ Stress $\sigma_{x z}$.

[9] D. Xie and A.M. Waas. Discrete cohesive zone model for mixed-mode fracture using finite element analysis. 73(13):1783-1796, September 2006.

[10] A. Ammar. The proper generalized decomposition: a powerful tool for model reduction. International Journal of Material Forming, 3(2):89-102, June 2010.

[11] F. Chinesta, P. Ladeveze, and E. Cueto. A short review on model order reduction based on proper generalized decomposition. Archives of Computational Methods in Engineering, 18(4):395-404, November 2011.

[12] F. Chinesta, A. Ammar, and E. Cueto. Recent advances and new challenges in the use of the proper generalized decomposition for solving multidimensional models. Archives of Computational Methods in Engineering, 17(4):327-350, December 2010.

[13] E. Pruliere, F. Chinesta, and A. Ammar. On the deterministic solution of multidimensional parametric models using the proper generalized decomposition. Mathematics and Computers in Simulation, 81(4):791-810, December 2010.

[14] P. Ladeveze and A. Nouy. On a multiscale computational strategy with time and space homogenization for structural mechanics. Computer Methods in Applied Mechanics and Engineering, 192(28-30):3061-3087, July 2003. 
FEM

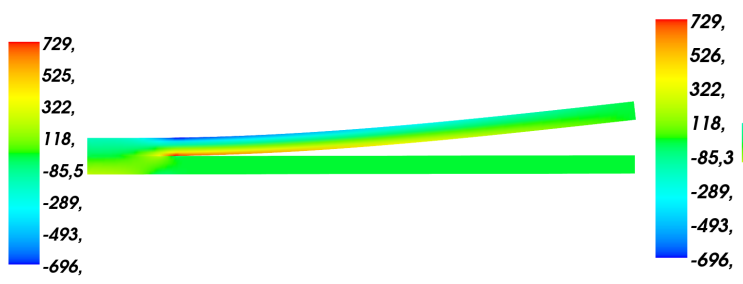

PGD

(a) Stress $\sigma_{x x}$

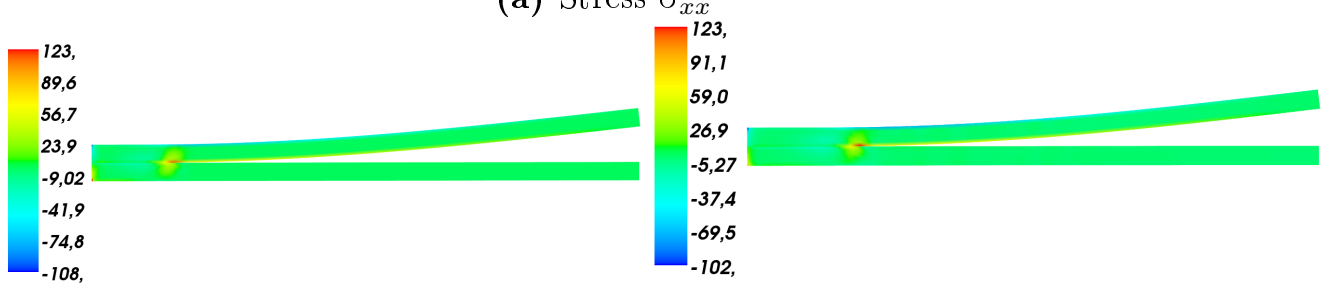

(b) Stress $\sigma_{z z}$

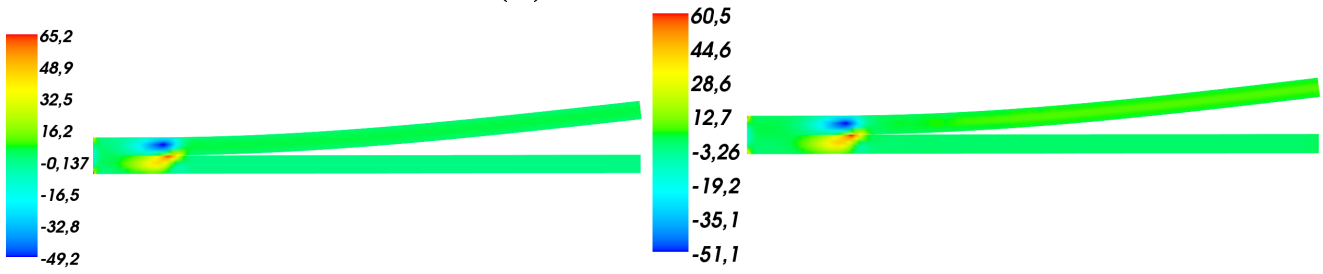

(c) Stress $\sigma_{x z}$

Figure 13: The distribution of longitudinal and shear stresses for the MMF specimen: (a) Stress $\sigma_{x x}$, (b) Stress $\sigma_{z z}$ and (c) Stress $\sigma_{x z}$. 


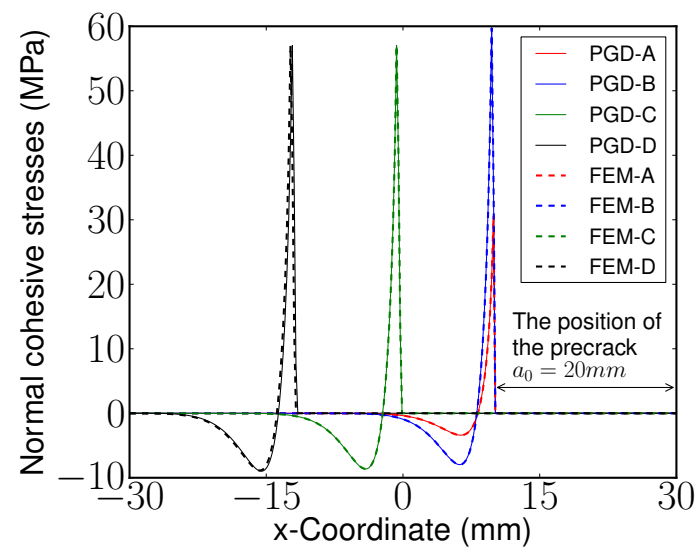

Figure 14: Normal cohesive stresses vs. position for different load stages of DCB test.

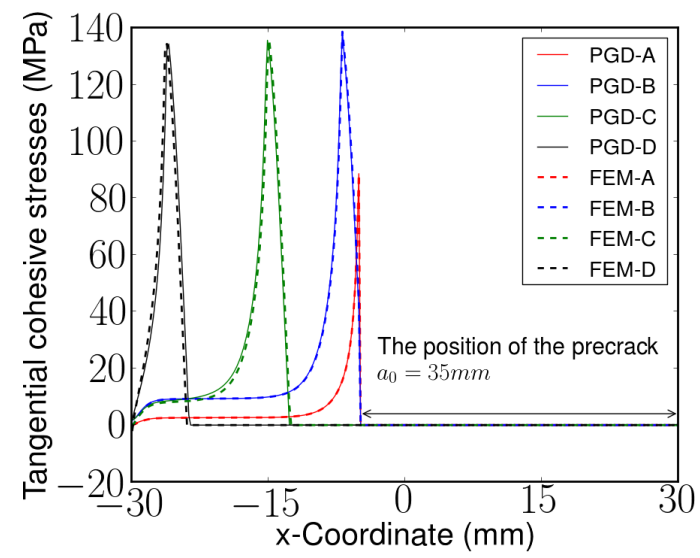

Figure 15: Tangential cohesive stresses vs. position for different load stages of ELS test.

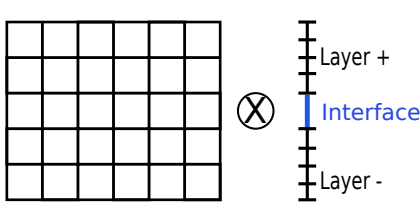

2D (x,y) / 1D (z) PGD discretization

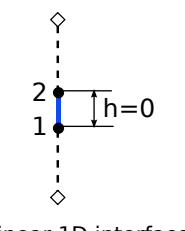

A linear 1D interface cohesive element

Figure 16: 2D/1D PGD discretization. 

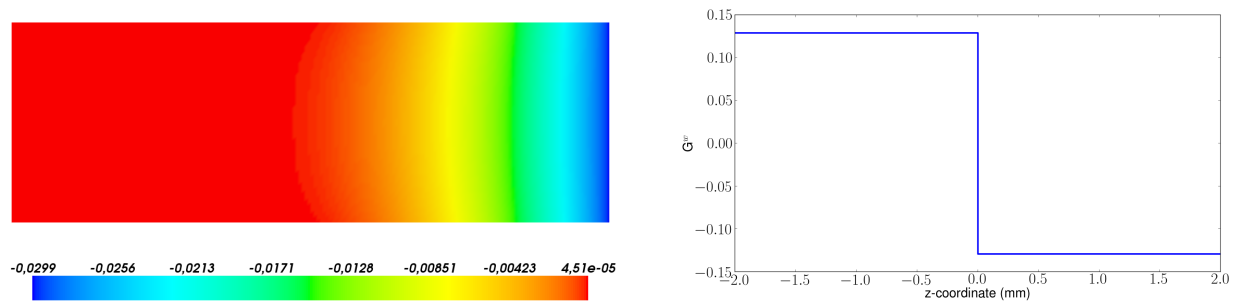

(a) $\mathbf{i}=\mathbf{1}$
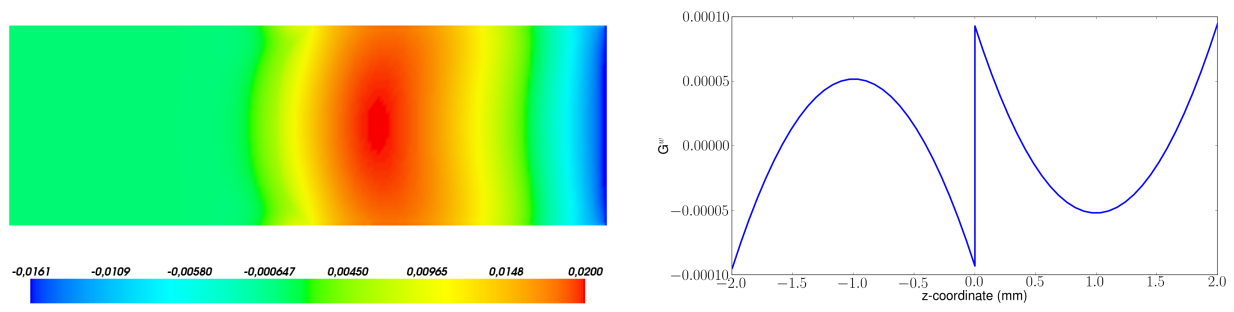

(b) $\mathrm{i}=\mathbf{2}$

Figure 17: Functions $F_{w}^{i}$ and $G_{w}^{i}$ in the separated representation of the displacement field: (a) $i=1$, (b) $i=2$.

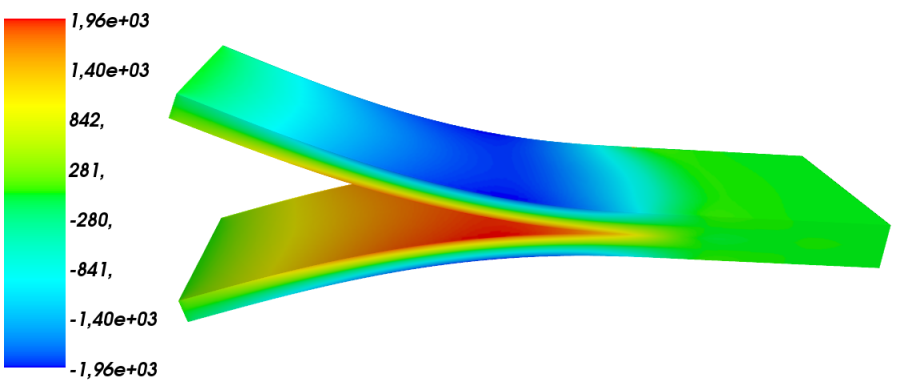

Figure 18: The $\sigma_{x x}$ stress distribution for the 3D DCB specimen. 

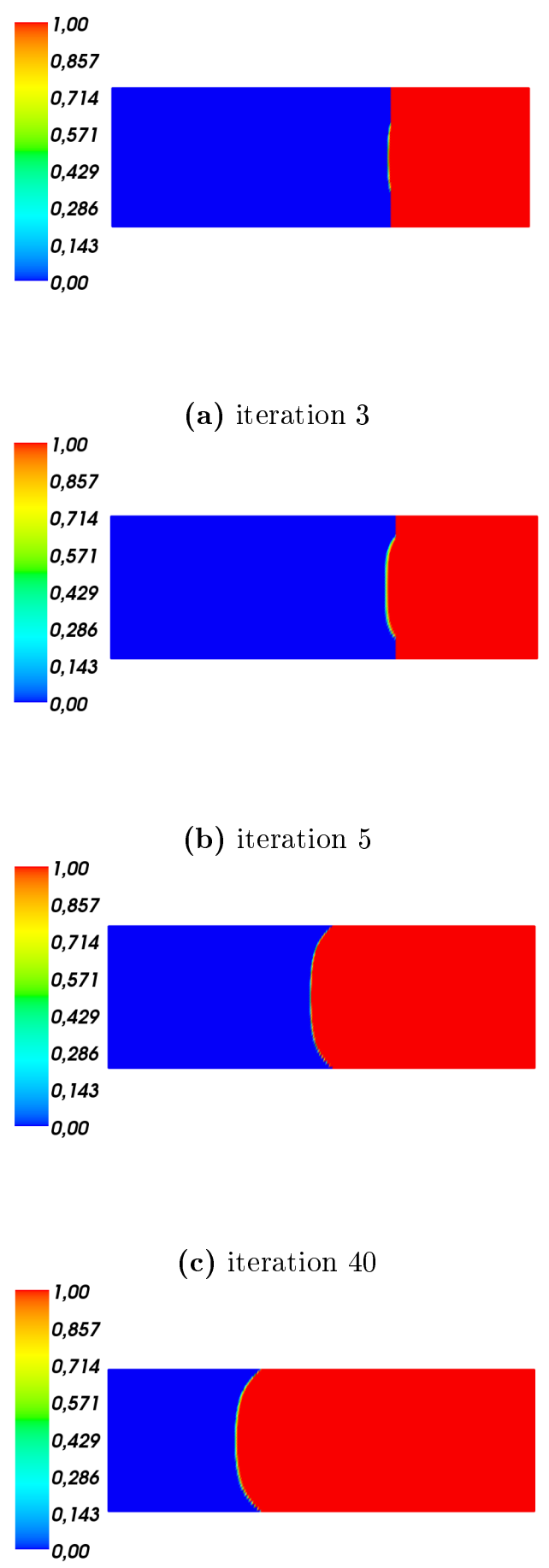

(d) final iteration

Figure 19: Crack surfaces of 3D DCB test: (a) iteration 3, (b) iteration 5, (c) iteration 40 and (d) final iteration. 
[15] P. Ladeveze, J.C. Passieux, and D. Neron. The latin multiscale computational method and the proper generalized decomposition. Computer Methods in Applied Mechanics and Engineering, 199(21-22):1287-1296, April 2010.

[16] A. Ammar, B. Mokdad, F. Chinesta, and R. Keunings. A new family of solvers for some classes of multidimensional partial differential equations encountered in kinetic theory modeling of complex fluids. Journal of NonNewtonian Fluid Mechanics, 139(3):153-176, December 2006.

[17] A. Ammar, B. Mokdad, F. Chinesta, and R. Keunings. A new family of solvers for some classes of multidimensional partial differential equations encountered in kinetic theory modelling of complex fluids: Part ii: Transient simulation using space-time separated representations. Journal of Non-Newtonian Fluid Mechanics, 144(2-3):98-121, July 2007.

[18] F. Chinesta, A. Ammar, and E. Cueto. On the use of proper generalized decompositions for solving the multidimensional chemical master equation. European Journal of Computational Mechanics, 19(1):53-64, 2010.

[19] F. Chinesta, A. Ammar, A. Falco, and M. Laso. On the reduction of stochastic kinetic theory models of complex fluids. Modelling and Simulation in Materials Science and Engineering, 15(6):639, September 2007.

[20] E. Pruliere, J. Ferec, F. Chinesta, and A. Ammar. An efficient reduced simulation of residual stresses in composite forming processes. International Journal of Material Forming, 3(2):1339-1350, September 2010.

[21] B. Bognet, F. Bordeu, F. Chinesta, A. Leygue, and A. Poitou. Advanced simulation of models defined in plate geometries: $3 \mathrm{~d}$ solutions with $2 \mathrm{~d}$ computational complexity. Computer Methods in Applied Mechanics and Engineering, 201-204:1-12, January 2012.

[22] A. Nouy. Generalized spectral decomposition method for solving stochastic finite element equations: Invariant subspace problem and dedicated algorithms. Computer Methods in Applied Mechanics and Engineering, 197(5152):4718-4736, October 2008.

[23] A. Nouy and O.P. Le Maître. Generalized spectral decomposition for stochastic nonlinear problems. Journal of Computational Physics, 228(1):202-235, January 2009.

[24] P. Vidal, L. Gallimard, and O. Polit. Composite beam finite element based on the proper generalized decomposition. Computers \& Structures, 102103:76-86, July 2012.

[25] P. Vidal, L. Gallimard, and O. Polit. Proper generalized decomposition and layer-wise approach for the modeling of composite plate structures. International Journal of Solids and Structures, 50(14-15):2239-2250, July 2013. 
[26] G. Alfano and M. A. Crisfield. Finite element interface models for the delamination analysis of laminated composites: mechanical and computational issues. International Journal for Numerical Methods in Engineering, 50(7):1701-1736, March 2001.

[27] J. Chen, M. Crisfield, A. J. Kinloch, E. P. Busso, F. L. Matthews, and Y. Qiu. Predicting progressive delamination of composite material specimens via interface elements predicting progressive delamination of composite material specimens via interface elements. Mechanics of Composite Materials and Structures, 6(4):301-317, 1999.

[28] M.J. Lee, T.M. Cho, W.S.Kim, B.C. Lee, and J.J. Lee. Determination of cohesive parameters for a mixed-mode cohesive zone model. International Journal of Adhesion and Adhesives, 30(5):322-328, July 2010.

[29] A. Turon, C.G. Davila, P.P. Camanho, and J. Costa. An engineering solution for mesh size effects in the simulation of delamination using cohesive zone models. Engineering Fracture Mechanics, 74(10):1665-1682, July 2007.

[30] A. Turon, P.P. Camanho, J. Costa, and J. Renart. Accurate simulation of delamination growth under mixed-mode loading using cohesive elements: Definition of interlaminar strengths and elastic stiffness. Composite Structures, 92(8):1857-1864, July 2010.

[31] T. Vandellos, N. Carrere, and C. Huchette. Development of computational strategy to model delamination in composite structures. In Comptes Rendus des JNC 16, Toulouse, 2009.

[32] N. Valoroso, S. Sessa, M. Lepore, and G. Cricri. Identification of mode-i cohesive parameters for bonded interfaces based on dcb test. Engineering Fracture Mechanics, 104:56-79, May 2013.

[33] B.R.K. Blackman, A.J. Brunner, and J.G. Williams. Mode ii fracture testing of composites: a new look at an old problem. Engineering Fracture Mechanics, 73(16):2443-2455, November 2006.

[34] M.F.S.F. de Moura and A.B. de Morais. Equivalent crack based analyses of enf and els tests. Engineering Fracture Mechanics, 75(9):2584-2596, June 2008.

[35] P.W. Harper and S.R. Hallett. Cohesive zone length in numerical simulations of composite delamination. Engineering Fracture Mechanics, 75(16):4774-4792, November 2008.

[36] A. Ammar, F. Chinesta, E. Cueto, and M. Doblaré. Proper generalized decomposition of time-multiscale models. International Journal for $\mathrm{Nu}$ merical Methods in Engineering, 90(5):569-596, May 2012. 
[37] L. Tàvara, V. Mantič, A. Salvadori, L.J. Gray, and F. París. Cohesivezone-model formulation and implementation using the symmetric galerkin boundary element method for homogeneous solids. Computational Mechanics, 51(4):535-551, April 2013. 